\title{
Capparaceae Juss. del departamento del Atlántico, Colombia
}

\section{Capparaceae Juss. from Atlántico deparment, Colombia}

\author{
Aura Carolina Aguirre De la Hoz ${ }^{a^{*}}$ \\ Thirza Ruiz Zapata ${ }^{\mathrm{b}}$
}

Recepción: 17 de noviembre de 2016

Aceptación: 29 de diciembre de 2016

\begin{abstract}
Capparaceae Juss. is a widely distributed family in tropical and subtropical regions, particularly in arid and semi-arid areas. The principal objetive of this research was to realize the taxonomic, morphological, etnobotanical and chorological study of the taxa of the family Capparaceae in the Atlántico department (Colombia); the department was crossed and specimens were collected, which were processed according to classical taxonomic techniques. As a result, a synopsis of the Capparaceae family is presented. It includes keys for the separation of the taxa and descriptions of the morphological characters of the species that grow in the department, as well as their synonyms, common nouns and uses. Seven genera (Belencita, Capparidastrum, Crateva, Cynophalla, Monilicarpa, Morisonia and Quadrella) and fourteen species are reported. Cynophalla is the most diverse genus, in addition, Cynophalla polyantha (Triana \& Planch.) Cornejo \& Iltis is registred for the first time in the Atlántico department.
\end{abstract}

Keywords: morphology, Cynophalla, distribution, taxonomy.

\section{Resumen}

Capparaceae Juss. es una familia de distribución amplia en regiones tropicales y subtropicales, particularmente en zonas áridas y semiáridas. El objetivo de este trabajo fue realizar el estudio taxonómico, morfológico, etnobotánico y corológico de los taxones de la familia Capparaceae presentes en el departamento del Atlántico (Colombia); para esto se recorrió el departamento y se recolectaron especímenes, los cuales se procesaron según técnicas taxonómicas clásicas. Como resultado se presenta una sinopsis de la familia Capparaceae. Se incluyen claves para la separación de los taxones y descripciones de los caracteres morfológicos de las especies que crecen en el departamento, así como también sus sinónimos, los nombres comunes y los usos. Se reportan siete géneros (Belencita, Capparidastrum, Crateva, Cynophalla, Monilicarpa, Morisonia y Quadrella) y catorce especies siendo Cynophalla el género más diverso entre ellos; además, se registra por primera vez Cynophalla polyantha (Triana \& Planch.) Cornejo \& Iltis en el departamento del Atlántico.

Palabras claves: morfología, Cynophalla, distribución, taxonomía.

Departamento de Biología, Universidad del Atlántico. Barranquilla, Colombia

Autor de Correspondencia: auraaguirre61@gmail.com

Instituto de Botánica Agrícola, Facultad de Agronomía, Universidad Central de Venezuela, Maracay 2101, Estado Aragua, Apartado Postal 4579. Venezuela. thirzar2409@yahoo.com 


\section{Introducción}

La familia Capparaceae Juss. según APG III y IV [1,2] fue ubicada dentro del orden Brassicales Bromhead. El primero en nombrar la familiar fue Jussieu [3] proponiendo el nombre de Capparides. Posteriormente, De Candolle [4], Benthan y Hooker [5] y Eichler [6] acogen el nombre Capparideae. En 1947, Lanjow y Sprague para el ICBN [7], proponen conservar el nombre Capparidaceae, sin embargo el Código de Montreal [8] en su Apéndice II (Nomina Familiarum Conservanda) establece un listado de nombres que deben conservarse entre los que se encuentra el nombre Capparaceae refiriéndose a la familia (este no había sido utilizado antes). En los últimos años, a partir de estudios moleculares $[9,10] \mathrm{el}$ género tipo (Capparis L.) quedó restringido al Viejo Mundo y las especies del Nuevo Mundo debieron ser reordenadas en otros géneros: Anissocapparis Cornejo \& Iltis, Beautempsia (Benth. \& Hook.) Gaudich., Calanthea (DC.) Miers, Capparicordis Mart., Capparidastrum (DC.) Hutch., Colicodendron Mart., Cynophalla (DC.) J. Presl, Mesocapparis (Eichl.) Cornejo \& Iltis, Monilicarpa Cornejo \& Iltis, Neocalyptrocalyx Hutch., Quadrella (DC.) J Presl, Sarcotoxicum Cornejo \& Iltis [11-23].

Actualmente, sus especies presentan una distribución en regiones tropicales y subtropicales [9, 24-30], especialmente en las zonas áridas [26,27,31], y pocas especies en climas templados [31,32], como la especie tipo Capparis spinosa L.; la familia reúne actualmente 45 géneros y alrededor de 700 especies, incluyendo el Viejo Mundo, en el Neotrópico está constituida aproximadamente por 19 géneros y 110 especies [30].

La familia Capparaceae además de ser dominantes en bosques secos, la familia ha sido señalada por ocupar los primeros puestos en importancia florística de bosques secos de algunos países Neotropicales. La mayoría de sus especies son perennifolias, ciertos autores recomiendan utilizarlas en la reforestación de áreas secas [30,31]. En algunos países las especies de esta familia son consideradas como potenciales recursos ornamentales [27], industriales [27,33], alimenticios [30] y medicinales [34], lo que demuestra el gran interés socioeconómico que tienen. En Colombia, los estudios con Capparaceae son escasos, son incluidas en estudios de taxonomía y la biología de algunos representantes de algunos géneros [35-39], así como también son nombradas en estudios florísticos y listados comentados de especies para la conservación $[40,41]$. En este contexto, este estudio tiene como propósito enriquecer el conocimiento actual de la diversidad florística del Caribe colombiano, y en especial, hacer aportes al conocimiento taxonómico, morfológico, etnobotánico y corológico de los taxones de la familia Capparaceae presentes en el departamento del Atlántico, Colombia.

\section{Metodología}

El área de estudio corresponde al departamento del Atlántico y forma parte de la región geográfica del Caribe colombiano. Presenta un clima cálido con una temperatura media anual de $27,8^{\circ} \mathrm{C}$, humedad relativa promedio de $81 \%$, precipitación promedio anual de $1034,1 \mathrm{~mm}$ [42]. Exhibe una temporada de sequía que va de diciembre a abril y una de lluvia de mayo a noviembre; y una elevación de 0 a 505 msnm [43].

Para el presente estudio se dividió el departamento del Atlántico en tres zonas (figura 1):

La primera zona es la correspondiente al litoral Caribe, que va desde Bocas de Ceniza hasta Galerazamba (depto. de Bolívar), de suelo árido, casi desértico y tierras poco fértiles, formado por playas, entre los municipios de Puerto Colombia, Tubará y Juan de Acosta.

La segunda es la zona central o de colinas formadas por ciénagas, sierras y serranías, estas últimas alcanzan los 521 metros sobre el nivel del mar.

La tercera zona corre paralela al río Magdalena hasta el desprendimiento del Canal del Dique, al margen izquierdo del río, cuyo terreno es periódicamente inundado y de relieve plano.

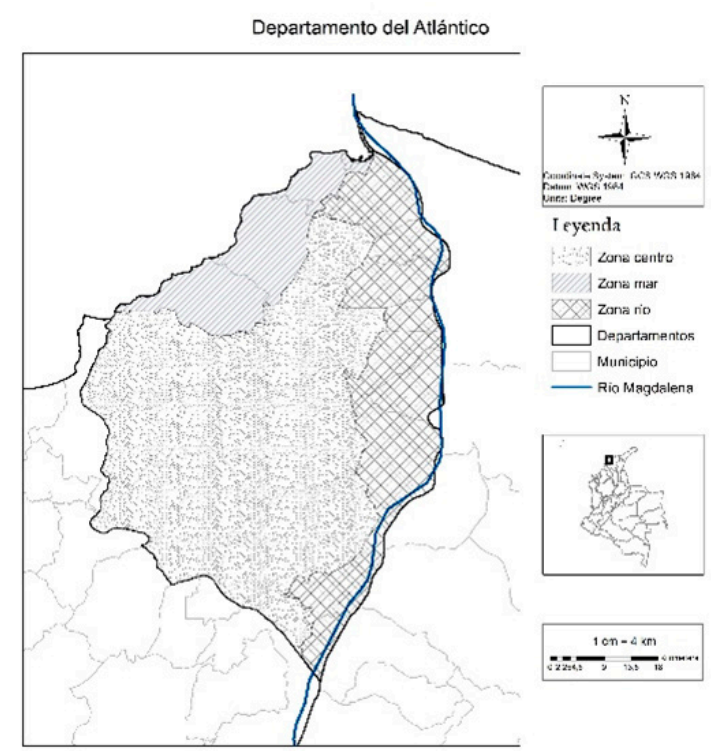

Figura 1. Departamento del Atlántico dividido en las tres zonas de vida descritas: zona centro, mar y río. 
Los ejemplares fueron recolectados mediante el método de muestreo botánico tradicional [44] y procesados en el Herbario DUGAND de la Universidad del Atlántico; la información sobre de distribución geográfica, nombres comunes y usos fueron tomados estrictamente en el departamento del Atlántico. Se revisaron las colecciones de los herbarios siguientes: Herbario Armando Dugand Gnecco (DUGAND), Herbario Federico Medem Bogotá (FMB) y el Herbario Nacional Colombiano (COL). Mediante el uso de claves de trabajos como los de Cornejo e Iltis [15,30], Cumana [27], Ruiz Zapata e Iltis [26], Ruiz Zapata [28,45], entre otros, y las bases de datos de Tropicos [46], The Plant List [47] y Jstor Global Plant [48], se identificaron los taxones recolectados en el departamento del Atlántico. Dentro de las descripciones de cada taxón se incluyen: nombre aceptado hasta la fecha, autor(es), referencia bibliográfica, sinónimos, descripción morfológica, nombres comunes y usos para el área de estudio, distribución geográfica, hábitat e ilustraciones de las especies. Las descripciones y claves taxonómicas fueron elaboradas a partir de los especímenes recolectados dentro del área delimitada.

\section{Resultados}

Se encontraron catorce especies incluidas en siete géneros de la familia Capparaceae en el departamento del Atlántico, siendo todas nativas. Los géneros reportados corresponden a Belencita, Capparidastrum, Crateva, Cynophalla, Monilicarpa, Morisonia y Quadrella. El género más diverso es Cynophalla con seis especies, los demás solo tienen una o dos. Se registra por primera vez para el Atlántico Cynophalla polyantha (Triana \& Planch.) Cornejo \& Iltis.

\subsection{Tratamiento taxonómico}

Capparaceae Juss., Gen. Pl. 242-243. 1789. T.: Capparis L.

Árboles, arbustos o lianas, glabros o con indumento simple, estrellado o lepidoto; ramas rectas o en forma de zig-zag, a veces con glándulas nectarias supraxilares (Cynophalla); hojas simples, o rara vez trifolioladas (Crateva), alternas, con estípulas diminutas o ausentes; peciolos de longitud variable hasta casi ausentes, cuando muy largos con pulvínulo en ambos extremos; lámina ovada, elíptica, oblongo-elíptica, angosto-elíptica, obovada, oblanceolada, hastada hasta linear, base obtusa, cuneada, ligeramente cordada hasta hastada, ápice obtuso, agudo, acuminado hasta retuso, coriácea, papirácea o membranácea, glabra o con indumento variable; flores solitarias (Belencita) o en inflorescencias tipo racimos, corimbos y a veces formando panículas axilares, caulinares y/o terminales; flores hermafroditas, actinomorfas o zigomorfas, subtendidas por brácteas diminutas; cáliz con estivación valvada, imbricada o decusada, de 2 a 4 sépalos libres o ligeramente unidos, glabros o con indumento variable; nectarios 4 en forma de escamas o glándulas, o un tejido nectarífero dentro del hipanto (Crateva), opuestos a los sépalos y alternos a los pétalos; corola de estivación abierta o imbricada, con 4 pétalos libres, glabros o con indumento variable; androceo de 14 a 155 estambres, anteras basifijas o dorsifijas; gineceo sobre un ginóforo largo, diminuto o éste ausente; ovario cilíndrico, ovoide o globoso; estigma discoidal, cupuliforme o inconspicuo, sésil; fruto capsular o anfisarco, cilíndrico, oblongocilíndrico, globoso o globoso-ovoide, moniliforme (Monilicarpa), toruloso o no, liso, rugoso o verrugoso, dehiscente o indehiscente, endocarpo anaranjado, rojo, blanco, crema o púrpura; semillas variables en número, elipsoidales, obovadas, ovoides o reniformes, con arilo de color blanco, crema, anaranjado o rojo; embrión de color verde, blanco o crema.

\subsection{Clave para los géneros de la familia Capparaceae en el departamento del Atlántico}

1. Hojas trifolioladas. Corola de estivación abierta. Crateva

1'. Hojas simples o claramente unifolioladas......... 2

2. Sépalos connatos en gran parte de su longitud....... 3 2'. Sépalos libres o ligeramente unidos en la base. .............................................. 4

3. Cáliz abriendo en dos lóbulos o sólo por un lado a manera de espata; estructuras sepaloides 1-2 o ausentes. Indumento estrellado. Belencita

3'. Cáliz abriendo irregularmente en 2-4 lóbulos. Estructuras sepaloides ausentes. Indumento lepidoto peltado-laciniado. Morisonia

4. Cálizde 4 sépalos en dos seriesy con estivación imbricada; glándulas nectarias supraxilares presentes............................... Cynophalla

4'. Cáliz de 4 sépalos en una serie y con estivación abierta o valvada; glándulas supraxilares ausentes. .............................. 5 
5. Indumento de tricomas estrellados o de escamas peltadas; hojas jóvenes conduplicadas. Quadrella

5'. Indumento de tricomas simples o ausente; hojas jóvenes no conduplicadas. 6

6. Fruto linear moniliforme. Embrión verde. Inflorescencia tipo racimo. Monilicarpa

6'. Fruto globoso o cilíndrico no moniliforme. Embrión blanco-cremoso. Inflorescencia tipo corimbo..... Capparidastrum

1. Belencita H. Karsten. en Koch, Berliner Allg. Gartenzeitung 25 (4): 25. 1857. T.: B. hagenii $\mathrm{H}$. Karsten.

Stuebelia Pax en Engler, Bot. Jahrb. Syst. 9:39. 1888.

1.1. Belencita nemorosa (Jacq.) Dugand, Caldasia 2 (9): 371. 1944.

Capparis nemorosa Jacq., Enum. Pl. Carib. 24. 1760; Select. Stirp. Amer. Hist. 164, t. 181 fig. 69. 1763; Belencita hagenii Karst., en C. Koch, Berliner Allg. Gartenzeitung 25 (4): 25, t. 1. 1857; Stuebelia nitida Pax, en Engl. Bot. Jahrb. 9: 39, t. 2 fig. 1-11. 1887-1888; Stuebelia nemorosa (Jacq.) Dugand en Trop. Woods 43: 15. 1935.

Árbol perennifolio; hojas alternas, simples; lámina ovada, base obtusa a ligeramente cordada y ápice agudo, coriácea; hojas y ramas juveniles pubescentes en haz y envés, adultas pubescentes en el envés, con indumento estrellado; flores solitarias, terminales o axilares hacia los extremos de las ramas, hermafroditas, actinomorfas, subtendidas por brácteas diminutas; cáliz gamosépalo, abriendo en dos lóbulos o sólo por un lado a manera de espata, pubescente; estructuras sepaloideas de 1 a 2 o ausentes, cuando presentes libres, alternas a los sépalos, glabras; glándulas nectarias 4, opuestas a cada sépalo y alternas a los pétalos; corola dialipétala, de estivación imbricada, con 4 pétalos libres, romboides, de base atenuada, de color blanco; androceo de 15 a 17 estambres, glabros; anteras dorsifijas; gineceo sobre un ginóforo purpúreo, ovario oblongo, verdoso; estigma cupuliforme, sésil; fruto anfisarco, globoso-ovoide, indehiscente, lustroso, de color verde, endocarpo cremoso; semillas pocas en número, reniformes, con arilo crema; embrión de color blanco (figura 2).

Distribución global: Colombia y Venezuela.
Hábitat: Bosques deciduos bajos, espinares y cardonales. Hasta altitudes de $245 \mathrm{~m}$.

Nombre común: Calabacillo.

Usos: Fruto ingerido por los monos aulladores colorados (Alouatta seniculus).

Ejemplares examinados: ATLÁNTICO: Municipio Juan de Acosta: Reserva Camp. La Montaña, 245 msnm, 14 Mar 2015, fl./fr., A. Aguirre D. \& E. Ortíz 22 (DUGAND). Municipio Luruaco: San Juan de Tocagua, 46 msnm, 24 May 2015, fr., A. Aguirre D. \& E. Ortíz 38 (DUGAND).

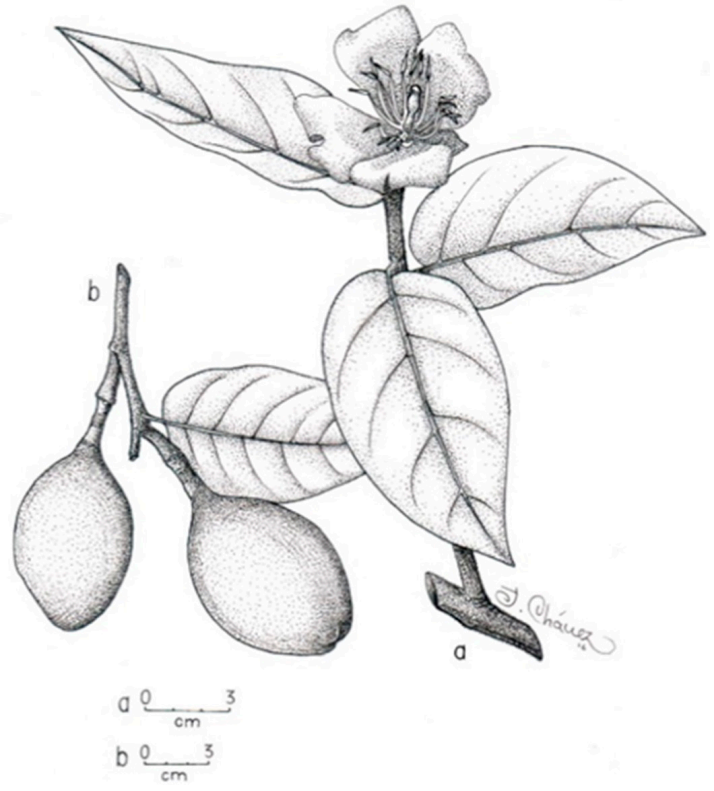

Figura 2. Belencita nemorosa (Jacq.) Dugand.: a. Rama con flor; b. Frutos; a, b, basado en A. Aguirre D. \& E. Ortiz 22.

2. Capparidastrum (DC.) Hutch., Gen. Fl. Pl. 2: 309. 1967. LT.: Capparis frondosa Jacq. (Rankin \& Greuter 2004).

Capparis sect. Capparidastrum DC., Prodr. 1: 248. 1824; Capparis subg. Capparidastrum (DC.) Eichl., en Mart, Fl. Bras. 13(1): 269, 278. 1865.

Clave para el género Capparidastrum en el departamento del Atlántico

1. Hojas dispuestas en pseudoverticilos; peciolos de longitud variable. Fruto cilíndrico, algo toruloso, dehiscente. C. frondosum

1'. Hojas dispuestas regularmente en el tallo; peciolos de longitud constante. Fruto globoso, indehiscente. C. pachaca 
2.1. Capparidastrum frondosum (Jacq.) Cornejo \& Iltis, Harvard Pap. Bot. 13: 232. 2008.

Capparis frondosa Jacq., Enum. Syst. P1. 24 1760; Capparis triflora Mill., Gard. Dict. ed. 810. 1768; Capparis commutata Spreng., Neue Entdeck. Pflanzenk. 3: 57. 1822; Capparis cuneata DC., Prodr. 1: 249. 1824; Pleuteron frondosa (Jacq.) Raf., Sylva Tellur. 109. 1838; Uterveria frondosa (Jacq.) Bertol., Hort. Bonon. Pl. Nov. 2: 8. 1839; Capparis stenophylla Standl., J. Wash. Acad. Sci. 13: 437. 1923.

Arbusto o arbolito perennifolio; hojas alternas, simples, dispuestas en pseudoverticilos de trecho en trecho a lo largo del tallo, con par de estípulas; peciolos de longitud variable en el mismo pseudoverticilo, con pulvínulo en ambos extremos en las hojas con peciolos más largos; lámina elíptica a ovada, base cuneada a obtusa, en algunos casos desigual, y ápice agudo a obtuso, margen ligeramente ondulado, papirácea a coriácea, glabra; inflorescencia racimosa en corimbos caulinares y terminales, brácteas a lo largo del pedúnculo de ésta; flores hermafroditas, actinomorfas, subtendidas por brácteas diminutas; pedicelo pubérulo; cáliz de estivación abierta, de 4 sépalos libres, circulares a obovados, pubérulo, persistente; glándulas nectarias opuestas a cada sépalo y alternas a los pétalos; corola de estivación imbricada, con 4 pétalos libres, obovados, de color verduzco; androceo de 60 a 72 estambres, glabros; anteras dorsifijas; gineceo sobre un ginóforo crema; ovario cilíndrico; estigma discoidal, sésil; fruto capsular, algo carnoso, cilíndrico-oblongo, toruloso, dehiscente, liso, purpúreo, endocarpo cremoso; semillas variables en número, obovadas a reniformes, con arilo blanco; embrión de color crema (figura 3).

Distribución global: América tropical.

Hábitat: Bosques deciduos del departamento. Hasta altitudes de $521 \mathrm{~m}$.

Nombres comunes: Sincogollo, contraprieta.

Usos: Esta especie es utilizada para el tratamiento de inflamaciones $y$, para las picaduras y mordeduras de animales venenosos.

Ejemplares examinados: ATLÁNTICO: Municipio Candelaria: 50 msnm, 11 Ene 1941, b. fl., A. Dugand \& R. Jaramillo 2775 (COL). Municipio Juan de Acosta: Reserva campesina La Montaña, 245 msnm, 14 Mar 2015, fl./fr., A. Aguirre D. \& E. Ortíz 29 (DUGAND); 14 Mar 2015, fr., A. Aguirre D. \& E. Ortíz 27 (MY). Municipio Luruaco: Carretera San Juan de Tocagua, 46 msnm, 24 May 2015, fl., A. Aguirre
D. \& E. Ortíz 39 (DUGAND); Reserva Los Rosales, 37 msnm, 07 Jun 2015, fr., A. Aguirre D. \& E. Ortíz 49 (COL, DUGAND). Municipio Palmar de Varela: 02-04 Ago 1943, fl., A. Dugand \& R. Jaramillo 3449 (COL). Municipio Piojó: Cerro el Palomar, 172 msnm, 01-31 Mar 2015, fr., A. Aguirre D. \& E. Ortíz 76 (COL, DUGAND); 172 msnm, 01-31 Mar 2015, b. fl., A. Aguirre D. \& E. Ortíz 77 (DUGAND); 01-31 Mar 2015, b. fl., A. Aguirre D. \& E. Ortíz 78 (DUGAND); 01-31 Mar 2015, fr., A. Aguirre D. \& E. Ortíz 81 (DUGAND); 01-31 Mar 2015, fr., A. Aguirre D. \& E. Ortíz 82 (DUGAND); Cerro la Vieja, 500 msnm, 19 Nov 2002, veg., H. Cuadros 5743 (DUGAND); 19 Nov 2002, veg., H. Cuadros 5717 (DUGAND). Municipio Repelón: Cerro Grande, 521 msnm, 20 Jul 2015, fr., A. Aguirre D. \& E. Ortíz 71 (DUGAND). Municipio Tubará: Camino a "El Chorro", 11 msnm, 22 Nov 2014, veg., A. Aguirre D. \& R. Fonseca 6 (DUGAND); Corrales de San Luis, 01-28 Feb 2008, fr., R. Fonseca \& M. P. Malagón M2P3 (DUGAND); Corrales de San Luis, 01-28 Feb 2008, fr., R. Fonseca \& M. P. Malagón T324 (DUGAND); Corrales de San Luis, 01-28 Feb 2008, fr., R. Fonseca \& M. P. Malagón T108 (DUGAND); Corregimiento Guaimaral, 10 Mar 2013, fl., D. de Castro \& K. Solano 1 (DUGAND); Inst. Agropecuario de Tubará, 250 msnm, 30 Mar 2008, b. fl., E. Pérez \& K. Redondo 2 (DUGAND); Loma Camarón, 23 Nov 2014, veg., A. Aguirre D. \& R. Fonseca 10 (DUGAND). Municipio Usiacurí: Arroyo Higuerón, 10 msnm, 05 Ene 1940, b. fl., A. Dugand \& H. García 2288 (COL); 05 Ene 1940, fl., A. Dugand \& H. Garcia 2305 (COL); Vereda Luriza, 154 msnm, 21 Abr 2010, fr., K. Banda-R., M. Alexander \& L. Olivares KBR112 (COL).

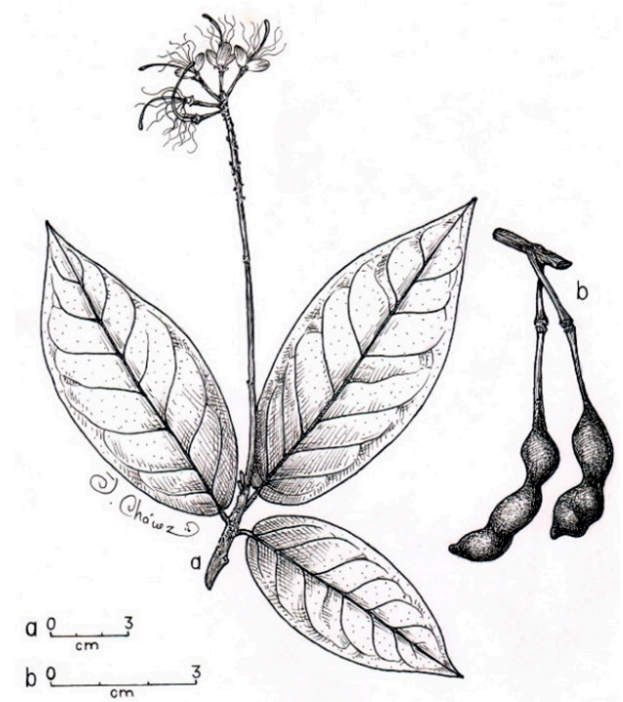

Figura 3. Capparidastrum frondosum (Jacq.) Cornejo \& Iltis.: a. Rama con inflorescencia; b. Frutos; a basado en D. de Castro \& K. Solano 1; b basado en R. Fonseca \& M. Malagón M2P3. 
2.2. Capparidastrum pachaca (Kunth) Hutch., Gen. Fl. Pl. 2: 310. 1967.

Capparis pachaca Kunth, Nov. Gen. Sp. 5: 93. 1821.

Árbol perennifolio; hojas alternas, simples, con par de estípulas; lámina elíptica a ovada, base obtusa a cuneada y ápice obtuso, margen ondulado, coriácea, glabra; inflorescencia racimosa en corimbos axilares y terminales, brácteas a lo largo del pedúnculo de ésta; flores hermafroditas, actinomorfas, subtendidas por brácteas diminutas; pedicelo pubérulo; cáliz urceolado, de estivación abierta, con 4 sépalos unidos formado en el ápice 4 dientes triangular-ovados, glabro a pubérulo, persistente; escamas nectaríferas opuestas a cada sépalo y alternas a los pétalos; corola de estivación imbricada, con 4 pétalos libres, obovados, crema; androceo de 48 a 63 estambres, glabros; anteras dorsifijas; gineceo sobre un ginóforo crema; ovario ovado a globoso; estigma cupuliforme, sésil; fruto anfisarco, globoso, indehiscente, rugoso, verde-amarillento; semillas variables en número, reniformes, inmersas en pulpa cremosa; embrión de color crema (figura 4).

Distribución global: América tropical.

Hábitat: Bosques deciduos y espinares de la zona de mar del departamento. Hasta altitudes de $400 \mathrm{~m}$.

Nombres comunes: Pachaco, totumito, calabacito, naranjito.

Usos: El fruto es comestible en algunas localidades del departamento como Usiacurí y Juan de Acosta.

Ejemplares examinados: ATLÁNTICO: Municipio Galapa: 100 msnm, 11 Oct 1932, veg., A. Dugand 130 (COL). Municipio Juan de Acosta: Serranía de Pajuancho, 59 msnm, 20 Ago 2015, fl., A. Aguirre D., L. Quijano \& D. Padilla 93 (DUGAND). Municipio Piojó: 400 msnm, 11 Ene 1940, fl., A. Dugand \& H. García Barriga 2412 (COL); 18 Ago 2011, veg., C. Castellanos, T. Riveros \& L. Olivares CCC546 (COL); Aguas Vivas, 01-31 May 2015, fr., A. Aguirre D. \& E. Ortíz 86 (DUGAND); Cerro el Palomar, 172 msnm, 01-31 Mar 2015, fl., A. Aguirre D. \& E. Ortíz 83 (DUGAND). Municipio Puerto Colombia: 23 Jul 1943, fl., A. Dugand \& R. Jaramillo 3236 (COL); 200 msnm, 07 Ene 1948, fr., F. Barkley \& G. Gutiérrez 1843 (COL, FMB); Km 17, 40 msnm, 30 Abr 1984, fr., E. Forero \& H. Cuadros 9928 (COL); Miramar, 25 msnm, 19 Dic 1945, fl., A. Dugand 4016 (COL); Municipio Tubará: Corrales de San Luis, 11 msnm, 22 Nov 2014, veg., A. Aguirre D. \& R. Fonseca 8 (DUGAND).

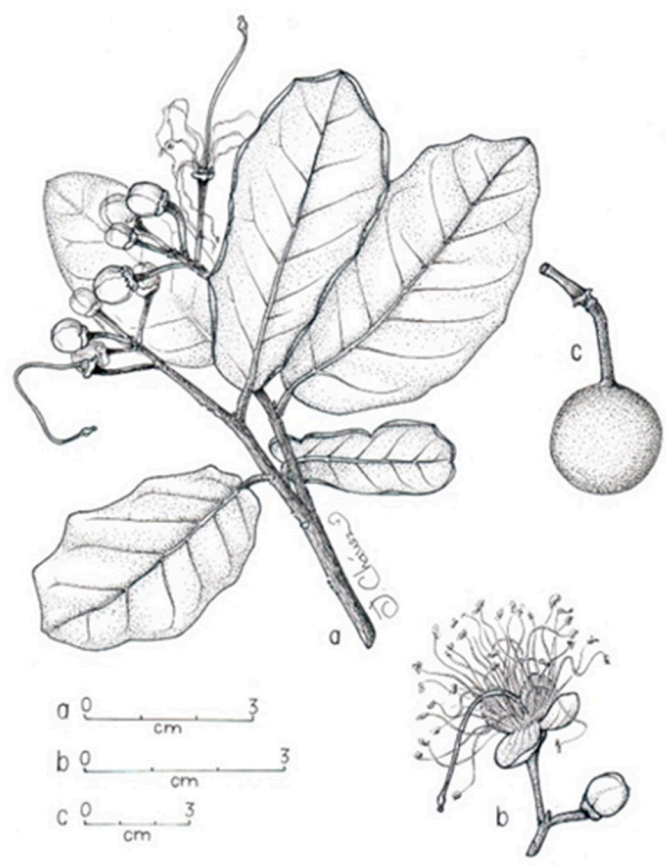

Figura 4. Capparidastrum pachaca (Kunth) Hutch.: a. Rama con flores y botones florales; b. Flor con botón floral; c. Fruto; a, b, basado en A. Aguirre D. \& E. Ortiz 83; c basado en A. Aguirre D. \& E. Ortiz 86.

3. Crateva L., Sp. Pl. 444. 1753. LT.: C. tapia L. (Corrêa da Serra 1800).

El nombre Crataeva L. solamente fue usado por el propio Linneo [49] en la edición 10 de Systema Naturae, pero el nombre válido es Crateva porque así fue publicado por él en Species Plantarum [50].

\subsection{Crateva tapia L. Sp. Pl. 444. 1753.}

Crateva gynandra L., Sp. Pl. ed. 2, 1: 636. 1762; Cleome arborea Schrad., Gött. Gel. Anz. 1: 707. 1821; Crataeva radiatiflora Ruiz \& Pavon ex DC., Prodr. 1: 243. 1824; Crataeva tapioides DC., Prodr. 1: 243. 1824; Crataeva acuminata DC., Prodr. 1: 243. 1824; Crataeva benthamii Eichler, Fl. Bras. 13(1): 265. 1865; Crataeva benthamii var. leptopetala Eichler, Fl. Bras. 13(1): 265. 1865; Crataeva bahiana Ule, Bot. Jahrb. Syst. 42: 202. 1908; Crataeva coriacea Herzog, Repert. Spec. Nov. Regni Veg. 7: 52. 1909; Crataeva glauca Lundell, Bull. Torrey Bot. Club 69: 389. 1942; Crataeva tapia var. glauca (Lundell) Standl. \& Steyerm., Publ. Field Mus. Nat. Hist., Bot. Ser. 23: 55. 1944.

Árbol deciduo; hojas alternas, compuestas, trifolioladas, con estípulas triangulares y diminutas; foliolos elípticos, foliolo central con base cuneada y ápice acuminado, foliolos laterales elípticos con base desigual y ápice acuminado, glabros, membranáceos; inflorescencia racimosa en 
corimbos terminales; flores hermafroditas, períginas, zigomorfas a asimétricas, subtendidas por brácteas diminutas; cáliz de estivación abierta, de 4 sépalos libres, ovados; corola de estivación abierta, de 4 pétalos libres, unguiculados, angosto-elípticos a obovados, blanco a crema-verdosos; androceo de 15 a 21 estambres; anteras basifijas, glabras; gineceo sobre un ginóforo de color rojizo; ovario ovoide; estigma discoide, subsésil; fruto anfisarco, globoso, ligeramente granuloso en su superficie, de color verde, indehiscente, endocarpo crema; semillas numerosas, reniformes, y con arilo crema; embrión blanco (figura 5).

Distribución global: América tropical y subtropical.

Hábitat: Bosques semideciduos, preferentemente cercanos a cursos de agua o en áreas estacionalmente inundables. Hasta altitudes de $10 \mathrm{~m}$.

Nombre común: Naranjito.

Usos: Especie ornamental adornando jardines y avenidas principales en la ciudad de Barranquilla.

Ejemplares examinados: ATLÁNTICO: Ciudad Barranquilla: Barrio Recreo, 03 Abr 2015, fl., A. Aguirre D. \& E. Ortíz 33 (DUGAND); Calle 85, 03 Oct 2015, fl., A. Aguirre D. 94 (DUGAND). Municipio Sabanagrande: Ciénaga El Convento, 03 Abr 2015, fr., A. Aguirre D. \& E. Ortíz 34 (DUGAND). Municipio Santo Tomás: Hacienda Puerto España, 5-10 msnm, 29 Abr 1960, veg., L. E. Mora 1393 (COL).

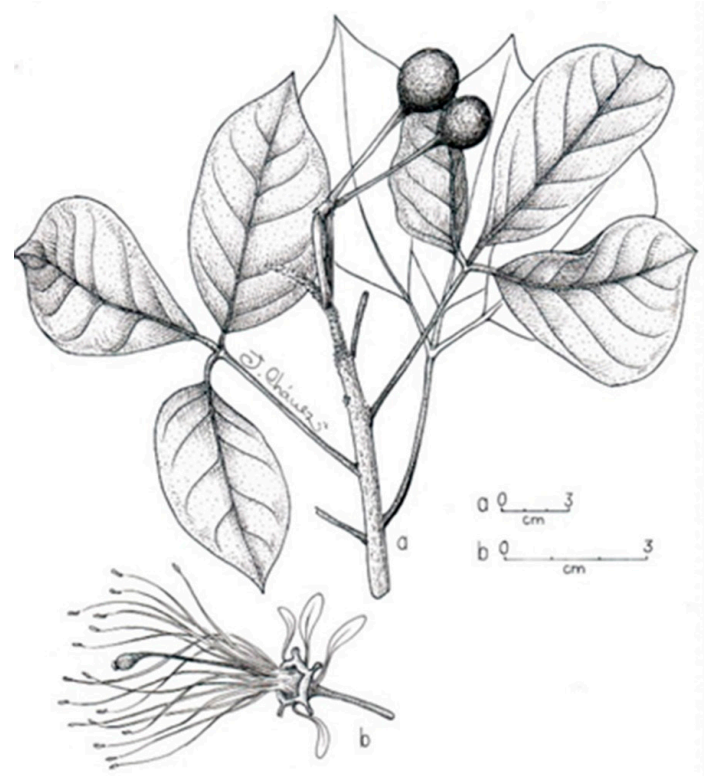

Figura 5. Crateva tapia L.: a. Rama con frutos; b. Flor; a basado en A. Aguirre D. \& E. Ortiz 34; b basado en A. Aguirre D. \& E. Ortiz 33.
4. Cynophalla (DC.) J. Pres1, Přir. Rostlin 2: 275. 1825. LT.: Capparis flexuosa (L.) L. [51].

Capparis sect. Cynophalla DC., Prodr. 1: 249. 1824; Capparis subg. Cynophalla (DC.) Eichl., en Mart, Fl. Bras. 13(1): 269. 1865.

Clave para el género Cynophalla en el departamento del Atlántico.

1. Hojas lineares con margen revoluto; ginóforo ausente o diminuto. C. linearis

1'. Hojas laminares de forma variada, nunca lineares; ginóforo presente. 2

2. Frutos de superficie verrugosa a levemente verrugosa; generalmente no torulosos. 3

2'. Frutos de superficie lisa; torulosos.

3. Arbustos. Hojas oblongo-elípticas. Frutos conspicuamente verrugosos de color púrpura a casi negro cuando maduros; endocarpo blanco. C. verrucosa

3'. Árboles. Hojas elípticas, a veces hastadas. Frutos levemente verrugosos de color verde con dos líneas de sutura púrpuras cuando maduros; endocarpo rojizo.

C. hastata

4. Arbustos; hojas sésiles, densamente pubescentes. Fruto liso de color púrpura a casi negro. C. sessilis

4'. Árboles o arbustos erectos o postrados; hojas pecioladas, glabras; frutos amarillorojizos con líneas de sutura rojizas.

5. Arbusto erecto o apoyado hasta lianoide. Hojas papiráceas a coriáceas con ápice retuso a ligeramente obtuso. C. flexuosa

5'. Árboles. Hojas membranáceas con ápice agudo a ligeramente acuminado...... C. polyantha

4.1. Cynophalla flexuosa (L.) J. Presl, Přir. Rostlin. 2: 275.1825 .

Morisonia flexuosa L., Pl. Jamaica Pug. 14. 1759; Capparis flexuosa (L.) L., Sp. Pl. ed. 2, 1: 722. 1762; Capparis saligna Vahl, Symb. Bot. 3: 66. 1794; Capparis subbiloba Kunth, Nov. Gen. Sp. 5: 90. 1821; Capparis lanceolata Ruiz \& Pav. ex DC., Prodr. 1: 249. 1824; Cynophalla saligna (Vahl) J.Presl, Prir. Rostlin 
2: 275. 1825; Capparis laetevirens Mart., Flora 22(1 Beibl.): 23. 1839; Capparis pluvialis Mart., Flora 22(1 Beibl.): 22. 1839; Capparis vellozoana Mart., Flora 22(1 Beibl.): 23. 1839; Colicodendron subbilobum (Kunth) Seem., Bot. Voy. Herald 78. 1852; Capparis cynophallophora var. saligna (Vahl) Griseb., Fl. Brit. W. I. 18. 1859; Capparis cynophallophora f. laetevirens (Mart.) Eichler, Fl. Bras. 13(1): 283. 1865; Capparis flexuosa var. saligna (Vahl) Fawc. \& Rendle, Fl. Jamaica 3: 234. 1914; Capparis eucalyptifolia Haught., Trop. Woods 20: 31. 1929; Capparis flexuosa var. cordifolia Kitan., God. Sofiisk. Univ. Biol. Fak., 2, Bot. Mikrobiol. Fiziol. Biokhim. Rast. 66: 31. 1974.

Arbusto o arbolito tortuoso, lianoide, perennifolio; ramas juveniles en forma de zig-zag, con glándulas nectarias supraxilares; hojas alternas, simples, con par de estípulas; lámina elíptica u oblanceolada, base cuneada y ápice retuso a ligeramente obtuso, coriácea a papirácea, glabra; inflorescencia racimosa en corimbos axilares o terminales, a veces agrupándose en panículas; flores hermafroditas, actinomorfas, subtendidas por brácteas diminutas; cáliz anisosépalo, de estivación decusada, de 4 sépalos libres dispuestos en dos series con los 2 externos más pequeños, redondos, glabros; glándulas nectarias opuestas a cada sépalo y alternas a los pétalos; corola de estivación imbricada, con 4 pétalos libres, obovados, de color blanco; androceo de 121 a 155 estambres, glabros; anteras dorsifijas; gineceo sobre un ginóforo verdoso; ovario cilíndrico; estigma discoidal, sésil; fruto capsular algo carnoso, cilíndrico, toruloso, dehiscente, liso, lustroso, amarillorojizo con dos líneas de sutura púrpuras, endocarpo rojo; semillas variables en número, elipsoidales, con arilo blanco; embrión de color verde (figura 6).

Distribución global: América tropical y subtropical.

Hábitat: Bosques espinares y cardonales, zona de mar de vegetación contraída. Hasta altitudes de $17 \mathrm{~m}$.

Nombres comunes: Ají, limpiadiente, arará.

Usos: Es utilizada como planta medicinal combinada con otras plantas para curar mordeduras de serpientes.

Ejemplares examinados: ATLÁNTICO: Ciudad Barranquilla: 12 Abr 1974, b.fl., T. Plowman 3519 (COL). Municipio Sabanalarga: La Peña, 17 msnm, 07 Jun 2015, b. fl., A. Aguirre D. \& E. Ortíz 51 (COL); 07 Jun 2015, fr., A. Aguirre D. \& E. Ortíz 52 (DUGAND). Municipio Santo Tomás: $5 \mathrm{msnm}, 29$ Abr 1960, b. fl., L. E. Mora 1444B (COL); 29 Abr 1960, b. fl., L. E. Mora 1489 (COL); Camino a la ciénaga de Santo Tomás, 5 msnm, 31 Ene 2015, b. fl., A. Aguirre D. \& J. Díaz 21 (DUGAND). Municipio Piojó: Aguas vivas, 01-31 May 2015 fl., A. Aguirre D. \& E. Ortíz 88 (COL); Correg. Guaibana, 08 Jun 2006, veg., C. Olaciregui C7 (DUGAND); Cerro El Palomar, 24 Ago 2011, veg., C. Castellanos, T. Riveros \& L. Olivares CCC577 (COL); Cerro La Vieja, 19 Nov 2002, veg., H. Cuadros 5713 (DUGAND). Municipio Puerto Colombia: $5 \mathrm{msnm}$, 16 Jul 1961, b. fl., A. Dugand 5728 (COL); Corredor universitario, 30 Jul 2015, fl., A. Aguirre D. \& H. Cuadros 90 (COL, DUGAND); Km 6, 10 Ago 1965, veg., A. Dugand 6959 (COL); 26 Abr 1967, b. fl., A. Dugand 7102 (COL); Lago del Caujaral, $5 \mathrm{msnm}$, 21 Jun 2013, fl., A. Muñoz-Acevedo, J. Rodríguez, L. Trillos, L. Mendez, J. Marrugo UN109 (COL). Municipio Tubará: Loma Camarón, 23 Nov 2014, veg., A. Aguirre D. \& R. Fonseca 18 (DUGAND).

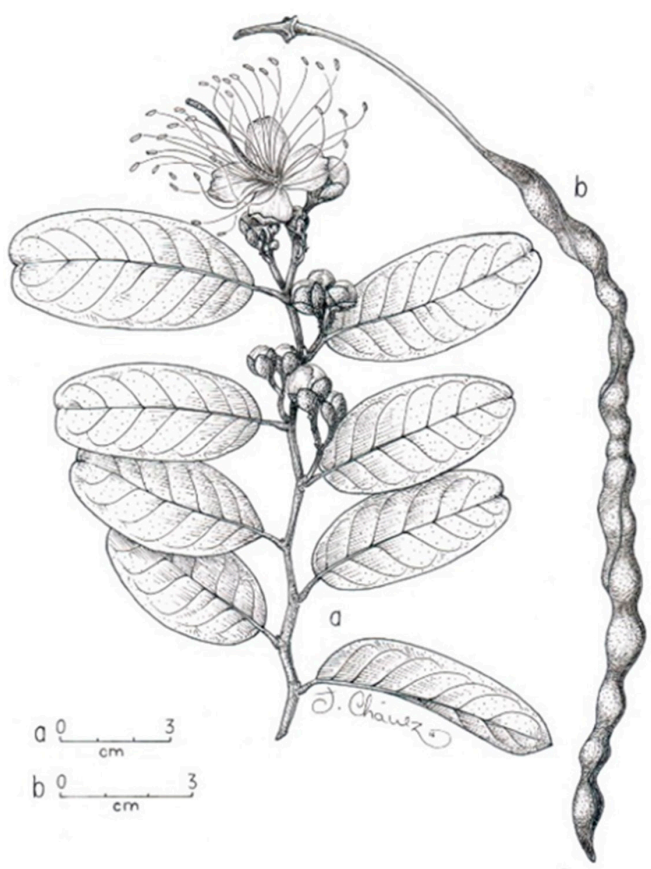

Figura 6. Cynophalla flexuosa (L.) J.Presl: a. Rama con flor y botones florales; b. Fruto; a basado en A. Dugand 7102; b basado en A. Aguirre D. \& E. Ortiz 52.

4.2. Cynophalla hastata (Jacq.) J.Presl, Přir. Rostlin. 2: 275.1825.

Capparis hastata Jacq., Enum. Syst. Pl. 23. 1760; Pleuteron hastata (Jacq.) Raf., Sylva Tellur. 109. 1838; Capparis coccolobifolia Mart. ex Eichler, Fl. Bras. 13(1): 284. 1865; Capparis coccolobifolia f. parvifolia Eichler, Fl. Bras. 13(1): 284. 1865; Capparis collina J.R.Johnst., Proc. Amer. Acad. Arts 40: 686. 1905; Capparis flexuosa f. hastata (Jacq.) Dugand, Caldasia 1(2): 51. 1941; Capparis hastata f. 
coccolobifolia (Mart. ex Eichler) Iltis \& Dugand, Fl. Venezuelan Guayana 4: 141. 1998.

Árbol perennifolio; ramas juveniles levemente en forma de zig-zag, con glándulas nectarias supraxilares; hojas alternas, simples, con par de estípulas diminutas; lámina oblongo-elíptica a ovada, y a veces hastada, base obtusa a retusa y ápice obtuso, coriácea, glabra, las de forma hastada con diminutas papilas en el haz; inflorescencia racimosa en corimbos terminales, a veces agrupándose en panículas; flores hermafroditas, actinomorfas, subtendidas por brácteas diminutas; cáliz anisosépalo, de estivación decusada, de 4 sépalos libres dispuestos en dos series con los 2 externos más pequeños, circulares a reniformes, glabros; glándulas nectarias opuestas a cada sépalo y alternas a los pétalos; corola de estivación imbricada, con 4 pétalos libres, suborbiculares a obovados, de color rosado; androceo de 96 estambres, glabros; anteras dorsifijas; gineceo sobre un ginóforo rojizo; ovario cilíndrico; estigma discoidal, sésil; fruto capsular algo carnoso, cilíndrico, escasamente toruloso, dehiscente, levemente verrugoso, verde-rojizo con dos líneas de sutura poco evidentes, endocarpo rojizo; semillas variables en número, elipsoidales, con arilo blanco; embrión de color verde (figura 7).

Distribución global: Antillas, Colombia y Venezuela.

Hábitat: Bosques deciduos, espinares y cardonales. Hasta altitudes de $245 \mathrm{~m}$.

Nombre común: Arará, limpiadiente, ají, contra.

Usos: Es utilizada como planta medicinal junto con otras plantas para curar mordeduras de serpientes.

Ejemplares examinados: ATLÁNTICO: Ciudad Barranquilla: 15 Ago 1964, veg., A. Dugand 6810 (COL); 15 Ago 1964, veg., A. Dugand 6809 (COL); Jinové, 22 Nov 1963, veg., A. Dugand 6559 (COL). Municipio Juan de Acosta: Reserva campesina La Montaña, 245 msnm, 14 Mar 2015, fl., A. Aguirre D. \& E. Ortíz 24 (DUGAND). Municipio Juanmina: 13 Jun 1967, fr., A. Dugand 7088 (COL). Municipio Luruaco: Carretera San Juan de Tocagua, 46 msnm, 24 May 2015, b. fl., A. Aguirre D. \& E. Ortíz 37 (DUGAND). Municipio Palmar de Varela: Hacienda El Paraíso, 12 Ene 1949, veg., A. Dugand \& R. Jaramillo 3241 (COL); 10 msnm, 28 Ene/ 8 Feb 1950, veg., A. Dugand 4450 (COL). Municipio Piojó: Aguas vivas, 01-31 May 2015, fr., A. Aguirre D. \& E. Ortíz 89 (DUGAND); Cerro El Palomar, 172 msnm, 01-31 May 2015, veg., A. Aguirre D. \& E. Ortíz 79 (DUGAND). Municipio Ponedera: 19 msnm, 03 Abr 2015, fl./fr., A. Aguirre D. \& E. Ortíz 36(COL, MY). Municipio Puerto Colombia:
01 Oct 1940, fr., A. Dugand 6834 (COL). 24 Jul 1943, fr., A. Dugand \& R. Jaramillo 3241 (COL); 10 msnm, 06 Jul 1963, veg., H. S. McKee 10440 (COL); 06 Jul 1963, fr., H. S. McKee 10439 (COL); 01 Oct 1964, fr., A. Dugand 6834 (COL); 25 Abr 1965, fr., A. Dugand 6902 (COL); 40 msnm, 30 Abr 1984, fr., E. Forero \& H. Cuadros 9927 (COL); 30 Abr 1984, fr., E. Forero \& H. Cuadros 9925 (COL). Municipio Santo Tomás: 10 msnm, 29 Abr 1960, fr., L. E. Mora 1443 (COL); 6 msnm, 29 Abr 1960, veg., L. E. Mora 1487 (COL); 29 Abr 1960, fr., L. E. Mora 1473 (COL). Municipio Tubará: Cuatrobocas, 23 Nov 2002, veg., H. Cuadros 5776 (DUGAND); Puerto Velero, 09 Ago 2015, fl./fr., A. Aguirre D. 91 (COL, MY).

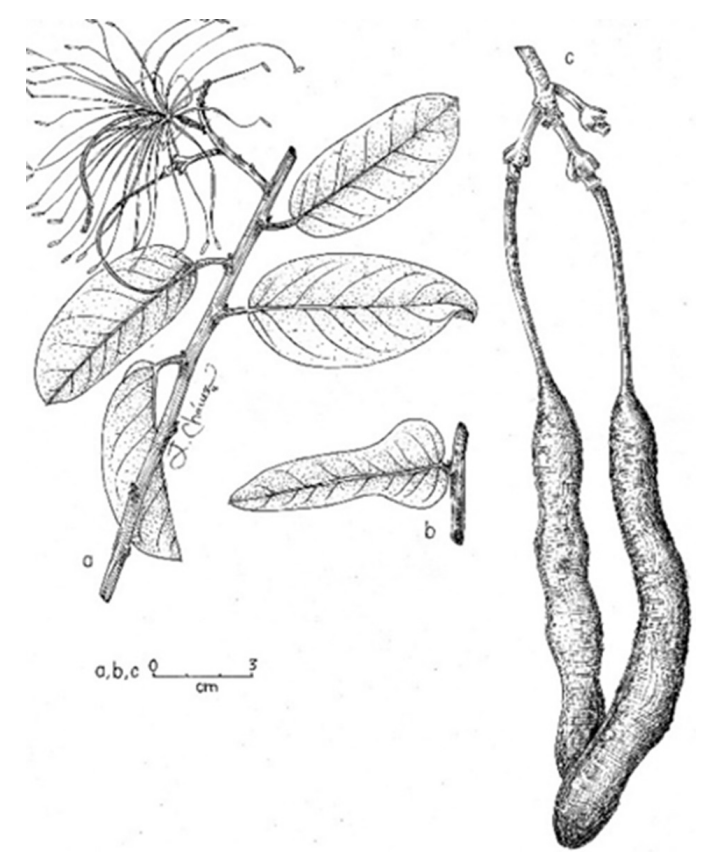

Figura 7. Cynophalla hastata (Jacq.) J.Presl: a. Rama con flor; b. Hoja juvenil; c. Frutos; a, c, basado en A. Aguirre D. \& E. Ortíz 36; b basado en A. Aguirre D. \& E. Ortíz 91.

4.3. Cynophalla linearis (Jacq.) J.Presl, Přir. Rostlin 2: 275.1825.

Capparis linearis Jacq., Enum. Syst. Pl. 24. 1760; Pleuteron linearis (Jacq.) Raf., Sylva Tellur. 109. 1838; Uterveria linearis (Jacq.) Bertol., Hort. Bonon. Pl. Nov. 2: 10. 1839; Capparis linearifolia Linden ex Turcz. Bull. Soc. Imp. Naturalistes Moscou 27(2): 3241854.

Arbusto o arbolito perennifolio; ramas juveniles levemente en forma de zig-zag, con glándulas nectarias supraxilares; hojas alternas, simples, con par de estípulas diminutas; lámina lineal con borde revoluto, base obtusa y ápice obtuso, coriácea, glabra; inflorescencia racimosa en corimbos axilares y terminales; flores hermafroditas, actinomorfas, subtendidas por brácteas diminutas; cáliz 
de estivación decusada e imbricada, de 4 sépalos libres dispuestos en dos series con los 2 externos más pequeños, circulares a elipsoidales, glabros; glándulas nectarias opuestas a cada sépalo y alternas a los pétalos; corola imbricada, con 4 pétalos libres, obovados, blancos; androceo de 64 estambres, glabros; anteras dorsifijas; gineceo sobre un ginóforo diminuto o éste ausente; ovario cilíndrico, subsésil; estigma discoidal, sésil; fruto capsular, algo carnoso, oblongo-cilíndrico, a veces toruloso; dehiscente, liso, anaranjado con dos líneas de sutura púrpuras, endocarpo amarillo a anaranjado; semillas variables en número, elipsoidales, con arilo blanco; embrión de color verde (figura 8).

Distribución global: Aruba, Curazao, Colombia y Venezuela.

Hábitat: Bosques espinares y cardonales de la zona de mar. Hasta altitudes de $200 \mathrm{~m}$.

Nombre común: Lengua de venado.

Usos: No conocidos.

Ejemplares examinados: ATLÁNTICO: Municipio Juan de Acosta: Playa Ferú, 10 Mar 1963, b. fl., A. Dugand 6216(COL). Municipio Piojó: Cerro el Palomar, 19 Ago 2011, veg., C. Castellanos, T. Riveros, L. Olivares CCC560 (COL). Municipio Puerto Colombia: 24 Jul 1943, fr., A. Dugand \& R. Jaramillo 3240 (COL); 200 msnm, 07 Ene 1948, veg., Fred. Barkley \& Gabriel Gutierrez 1853 (COL); 10 msnm, 06 Jul 1963, fr., H. S. McKee 10435 (COL); 30 Abr 1984, b. fl./fr., E. Forero \& H. Cuadros 9926 (COL); 40 msnm, 72 msnm, 21 Mar 2015, veg., A. Aguirre D. \& E. Ortíz 31 (DUGAND); 17 Jul 2015, fr., A. Aguirre D. \& E. Ortíz 62 (DUGAND).

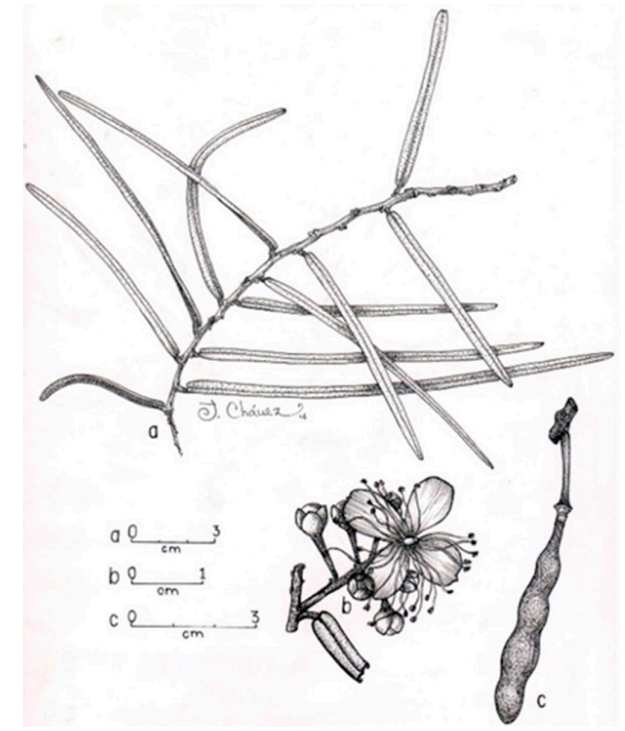

Figura 8. Cynophalla linearis (Jacq.) J.Presl: a. Rama con hojas; b. Flor con botones florales; c. Fruto; a basado en material fresco; b, c, basado en E. Forero \& H. Cuadros 9926.
4.4. Cynophalla polyantha (Triana \& Planch.) Cornejo \& Iltis, Harvard Pap. Bot. 13: 118. 2008.

Capparis polyantha Triana \& Planch., Ann. Sci. Nat., Bot. IV, 17: 76. 1862; Capparis flexuosa subsp. polyantha (Triana \& Planch.) Iltis, Fl. Venezuelan Guayana 4: 139. 1998.

Árbol perennifolio; ramas juveniles en forma de zig-zag, con glándulas nectarias supraxilares; hojas alternas, simples, con par de estípulas diminutas; lámina elíptica a ampliamente elíptica, base cuneada y ápice agudo a ligeramente acuminado, membranácea, glabra; inflorescencia racimosa en corimbos axilares y terminales, a veces agrupándose en panículas; flores hermafroditas, actinomorfas, subtendidas por brácteas diminutas; cáliz de estivación decusada de 4 sépalos libres dispuestos en dos series con los 2 externos más pequeños, circulares a obovados, glabros; glándulas nectarias opuestas a cada sépalo y alternas a los pétalos; corola de estivación imbricada, con 4 pétalos libres, obovados, de color crema-verdoso; androceo de 55 estambres, glabros; anteras dorsifijas; gineceo sobre un ginóforo verdoso; ovario cilíndrico; estigma discoidal, sésil; fruto capsular, algo carnoso, cilíndrico, toruloso, dehiscente, liso, lustroso, amarillo-rojizo con dos líneas de sutura púrpuras, endocarpo rojo; semillas variables en número, elipsoidales, con arilo blanco; embrión de color verde (figura 9).

Distribución global: Colombia, Venezuela, Bolivia y Argentina.

Hábitat: Bosques espinares y cardonales de la zona de mar. Hasta altitudes de $87 \mathrm{~m}$.

Nombre común: No conocidos.

Usos: No conocido.

Ejemplares examinados: ATLÁNTICO: Municipio Luruaco: Ciénaga San Juan de Tocagua, 5 msnm, 24 May 2015, fr., A. Aguirre D. \& E. Ortíz 41 (COL, DUGAND); Reserva Los Rosales, 37 msnm, 07 Jun 2015, veg., A. Aguirre D. \& E. Ortíz 44 (DUGAND); 07 Jun 2015, b. fl., A. Aguirre D. \& E. Ortíz 50 (DUGAND); 20 Jul 2015, fr., A. Aguirre D. \& E. Ortíz 66 (DUGAND). Municipio Sabanalarga: La Peña, 87 msnm, 07 Jun 2015, b. fl., A. Aguirre D. \& E. Ortíz 54 (MY). 


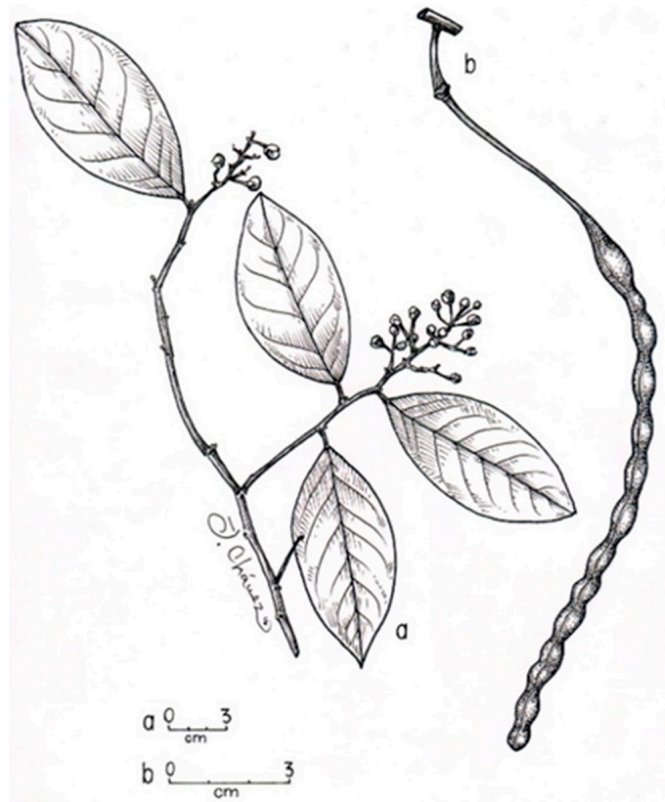

Figura 9. Cynophalla polyantha (Triana \& Planch.) Cornejo \& Iltis: a. Rama con botones florales; b. Fruto; a basado en A. Aguirre D. \& E. Ortiz 41; b basado en A. Aguirre D. \& E. Ortiz 50.

4.5. Cynophalla sessilis (Banks ex DC.) J.Presl, Přir. Rostlin. 2: 275. 1825.

Capparis sessilis Banks ex DC., Prodr. 1: 249. 1824; Capparis cardiophylla Turcz., Bull. Soc. Imp. Naturalistes Moscou 27(2): 325. 1854; Capparis securidacea Triana \& Planch., Ann. Sci. Nat., Bot. IV, 17: 77. 1862; Capparis usiacurina Dugand, Caldasia 1(2): 4. 1941; Capparis sessilis var. genuina Dugand, Caldasia 5(21): 56. 1948; Capparis sessilis var. securidacea (Triana \& Planch.) Dugand, Caldasia 5: 57. 1948.

Arbusto o arbolito perennifolio; ramas juveniles ligeramente en forma de zig-zag, pubescente, con glándulas nectarias supraxilares, ramas adultas con abundantes lenticelas; hojas alternas, simples, sésiles, con par de estípulas diminutas; lámina oblongo-elíptica a ovada, base cordada y ápice agudo a obtuso, papirácea a membranácea, pubescente en haz y envés; inflorescencia racimosa en corimbos terminales; flores hermafroditas, actinomorfas, subtendidas por brácteas diminutas; cáliz anisosépalo, de estivación decusada, de 4 sépalos libres dispuestos en dos series con los 2 externos más pequeños, circulares a elipsoidales, glabros; glándulas nectarias opuestas a cada sépalo y alternas a los pétalos; corola de estivación imbricada, con 4 pétalos libres, obovados, crema-verdosos; androceo de 89 a 96 estambres, glabros; anteras dorsifijas; gineceo sobre un ginóforo purpúreo; ovario cilíndrico; estigma discoidal, sésil; fruto capsular, algo carnoso, cilíndrico, toruloso, dehiscente, rojizo a purpúreo con dos líneas de sutura negras, endocarpo púrpura a rojo; semillas variables en número, reniformes, con arilo blanco; embrión de color verde (figura 10).

Distribución global: Colombia y Venezuela.

Hábitat: Bosques deciduos y espinares de la zona de mar, bosques ribereños. Hasta altitudes de $521 \mathrm{~m}$.

Nombre común: Olivo.

Usos: No conocidos.

Ejemplares examinados: ATLÁNTICO: Ciudad Barranquilla: 10 msnm, 29 Abr 1960, b. fl., L. E. Mora 1389 (COL). Municipio Luruaco: Ciénaga de Luruaco, 25 msnm, 24 May 2015, fr., A. Aguirre D. \& E. Ortíz 35A (MY); Reserva Los Rosales, 37 msnm, 07 Jun 2015, veg., A. Aguirre D. \& E. Ortíz 47 (DUGAND); 20 Jul 2015, fr., A. Aguirre D. \& E. Ortíz 65 (DUGAND); 20 Jul 2015, fr., A. Aguirre D. \& E. Ortíz 67 (DUGAND); 20 Jul 2015, fr., A. Aguirre D. \& E. Ortíz 69 (DUGAND); Vereda Mateo, 01 Ago 2012, b. fl., S. Villalobos 295 (DUGAND). Municipio Palmar de Varela: Hacienda El Paraíso, 10 msnm, 28 Ene/08 Feb 1950, b.fl./fr., A. Dugand 4433 (COL). Municipio Piojó: Cerro El Palomar, 172 msnm, 03 May 2015, veg., A. Aguirre D. 85 (DUGAND); Cerro La Vieja, 505 msnm, 11 Jul 2015, fr., A. Aguirre D. \& E. Ortíz 55 (DUGAND); 11 Jul 2015, b. fl., A. Aguirre D. \& E. Ortíz 56 (COL); 11 Jul 2015, veg, A. Aguirre D. \& E. Ortíz 57 (COL, DUGAND). Municipio Ponedera: Cerca de Martillo, 10 msnm, 29 Abr 1960, b. fl., L. E. Mora 1383 (COL). Municipio Repelón: Cerro Grande, 521 msnm, 20 Jul 2015, b. fl./fr., A. Aguirre D. \& E. Ortíz 74 (DUGAND). Municipio Usiacurí: 105 msnm, 01-30 Jun 1937, fr., A. Dugand 1098 (COL).

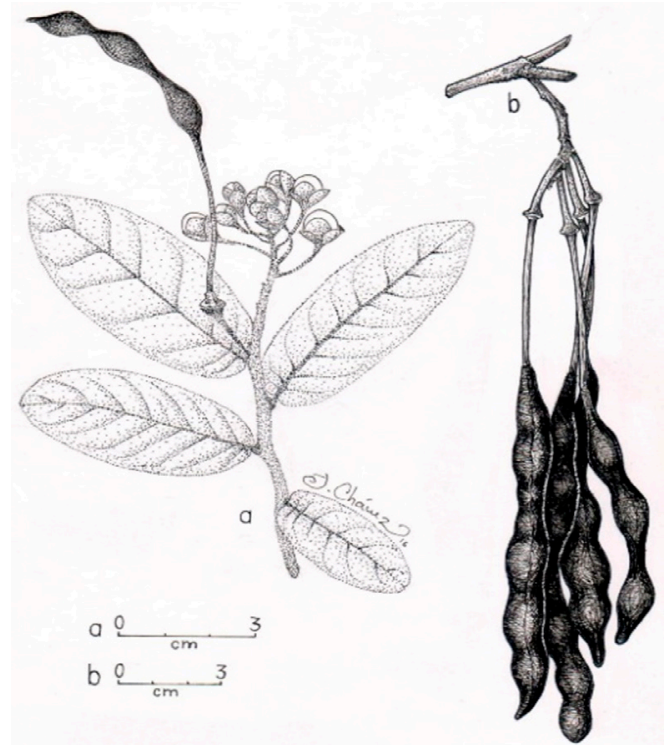

Figura 10. Cynophalla sessilis (Banks ex DC.) J.Presl: a. Rama con botones florales y fruto; $b$. Frutos; a basado en A. Dugand 4433; b basado en A. Aguirre D. \& E. Ortiz 55. 
4.6. Cynophalla verrucosa (Jacq.) J.Presl, Přir. Rostlin 2: 275. 1825.

Capparis verrucosa Jacq., Enum. Syst. Pl. 23. 1760; Capparis laeta Kunth, Nov. Gen. Sp. 5: 88. 1821; Cynophalla laeta (Kunth) J.Presl, Prir. Rostlin 2: 275. 1825; Uterveria verrucosa (Jacq.) Bertol., Hort. Bonon. Pl. Nov. 2: 9. 1839; Capparis brevipes Benth., Bot. Voy. Sulphur 65. 1844; Capparis rugulosa Turcz., Bull. Soc. Imp. Naturalistes Moscou 27(2): 326. 1854; Capparis blanchetii Briq., Annuaire Conserv. Jard. Bot. Genève 17: 394. 1914; Capparis trinitensis Urb., Notizbl. Bot. Gart. Berlin-Dahlem 8: 25. 1921.

Arbusto o arbolito perennifolio; ramas juveniles ligeramenteen forma de zig-zag, con glándulas nectarias supraxilares; hojas alternas, simples, subsésiles, con par de estípulas diminutas; lámina angosto elíptica a oblongo-elíptica, base cordada a obtusa y ápice agudo, obtuso hasta retuso, coriácea a papirácea, glabra; inflorescencia racimosa en corimbos terminales; flores hermafroditas, actinomorfas, subtendidas por brácteas diminutas; cáliz anisosépalo, de estivación decusada, de 4 sépalos libres dispuestos en dos series con los 2 externos más pequeños, circulares a elipsoidales, glabros; glándulas nectarias opuestas a cada sépalo y alternas a los pétalos; corola de estivación imbricada, con 4 pétalos libres, obovados, blancos; androceo de 55 estambres, glabros; anteras dorsifijas; gineceo sobre un ginóforo rojizo; ovario cilíndrico; estigma discoidal, sésil; fruto capsular, algo carnoso, oblongocilíndrico, no toruloso o a veces contraído en el centro, verrugoso, dehiscente, purpúreo a negro, endocarpo blanco; semillas variables en número, reniformes, con arilo blanco; embrión de color verde (figura 11).

Distribución global: Centroamérica, Colombia y Venezuela.

Hábitat: Bosques deciduos y espinares. Hasta altitudes de $521 \mathrm{~m}$.

Nombre común: Hueva de perro.

Usos: No conocido.

Ejemplares examinados: ATLÁNTICO: Ciudad Barranquilla: 100 msnm, 15 Feb 1961, veg., A. Dugand 5610 (COL). Municipio Juan de Acosta: 26 Abr 1984, fr., E. Forero \& H. Cuadros 9886 (COL); Reserva campesina La Montaña, 245 msnm, 14 Mar 2015, b. fl., A. Aguirre D. \& E. Ortiz 25 (MY); 14 Mar 2015, fl., A. Aguirre D. \& E. Ortiz 28 (DUGAND, MY). Municipio Luruaco: Ciénaga San Juan de Tocagua, 5 msnm, 24 May 2015, fl., A. Aguirre D. \& E. Ortíz 40 (DUGAND); Reserva Los Rosales,
37 msnm, 07 Jun 2015, b. veg., A. Aguirre D. \& E. Ortíz 45 (DUGAND). Municipio Palmar de Varela: Hacienda El Paraíso, 10 msnm, 05 Abr 1953, b. fl., A. Dugand 4617 (COL). Municipio Piojó: Aguas Vivas, 01-31 May 2015, fr., A. Aguirre D. \& E. Ortiz 87 (DUGAND); Cerro El Palomar, 172 msnm, 11 Jul 2015, fl., A. Aguirre D. \& E. Ortiz 75 (COL, DUGAND); Cerro La Vieja, 500 msnm, 19 Nov 2002, veg., H. Cuadros 5706 (DUGAND); 19 Nov 2002, veg., H. Cuadros 5720 (DUGAND); 505 msnm, 11 Jul 2015, fr., A. Aguirre D. \& E. Ortiz 58 (COL); 11 Jul 2015, fr., A. Aguirre D. \& E. Ortiz 59 (MY); 11 Jul 2015, veg., A. Aguirre D. \& E. Ortiz 60 (DUGAND). Municipio Puerto Colombia: Loma La Risota, 72 msnm, 21 Mar 2015, fl., A. Aguirre D. \& E. Ortiz 30 (MY); 21 Mar 2015, fr., A. Aguirre D. \& E. Ortiz 64 (DUGAND); Salgar, 20 Mar 1946, fl., A. Roncallo SD. (COL); 20 msnm, 27 Dic 1949, b. fl., A. Dugand 4410 (COL). Municipio Repelón: Cerro Grande, 521 msnm, 20 Jul 2015, veg., A. Aguirre D. \& E. Ortiz 72 (DUGAND). Municipio Santo Tomás: $10 \mathrm{msnm}, 29$ Abr 1960, fl./fr., L. E. Mora 1441 (COL). Municipio Tubará: Loma Camarón, 22 Nov 2014, veg., A. Aguirre D. \& R. Fonseca 7 (DUGAND); 23 Nov 2014, veg., A. Aguirre D. \& R. Fonseca 11 (DUGAND); 23 Nov 2014, veg., A. Aguirre D. \& R. Fonseca 15 (DUGAND); 23 Nov 2014, veg., A. Aguirre D. \& R. Fonseca 16 (DUGAND). Municipio Usiacurí: Vereda Luriza, 218 msnm, 23 Abr 2010, fr., K. Banda-R., M. Alexander \& L. Olivares KBR177 (COL).

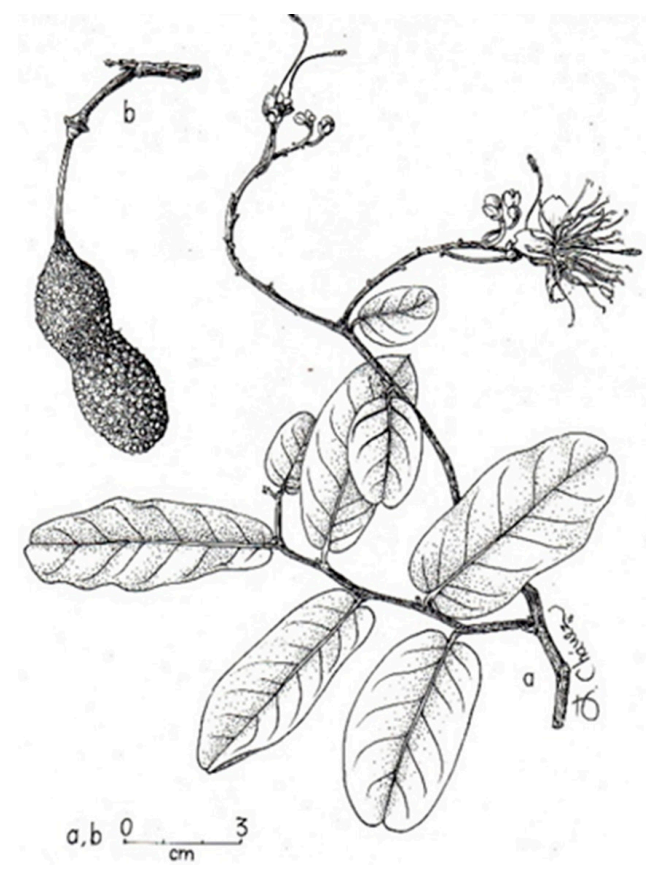

Figura 11. Cynophalla verrucosa (Jacq.) J.Presl: a. Rama con flor y botones florales; b. Fruto; a basado en A. Aguirre D. \& E. Ortíz 25; b basado en A. Aguirre D. \& E. Ortíz 30. 
5. Monilicarpa Cornejo \& Iltis, J. Bot. Res. Inst. Texas 2(1): 67-73. 2008. T.: Capparis tenuisiliqua Jacq.

5.1. Monilicarpa tenuisiliqua (Jacq.) Cornejo \& Iltis, J. Bot. Res. Inst. Texas 2(1): 70. 2008.

Capparis tenuisiliqua Jacq., Enum. Syst. Pl. 24. 1760; Capparis obovatifolia Kunth, Nov. Gen. Sp. 5: 92. 1821; Capparis viridiflora Kunth, Nov. Gen. Sp. 5: 92. 1821; Pleuteron tenuis Raf., Sylva Tellur. 109. 1838; Colicodendron obovatum Turcz., Bull. Soc. Imp. Naturalistes Moscou 27(2): 327. 1854; Uterveria tenuisiliqua (Jacq.) Bertol., Hort. Bonon. Pl. Nov. 2: 10. 1839; Capparis garciae Dugand, Caldasia 1(2): 45 1941; Capparidastrum tenuilisiliquum (Jacq.) Hutch., Gen. Fl. Pl. 2: 310. 1967.

Arbusto o arbolito semideciduo a brevemente deciduo; hojas alternas, simples, con par de estípulas diminutas; peciolos de longitud variable, con pulvínulo en ambos extremos; lámina elíptica a ovalada, base obtusa a ligeramente cordada y ápice agudo, membranácea, hojas y ramas jóvenes pubescentes, adultas glabras; inflorescencia en racimos terminales; flores hermafroditas, actinomorfas, subtendidas por brácteas diminutas; indumento de tricomas simples; cáliz de estivación abierta, de 4 sépalos unidos, triangulares, glabros a pubérulos, ciliados en el borde; escamas nectarias 4 , triangulares, opuestas a los sépalos y alternas a los pétalos, dispuestas en el borde de un pequeño hipanto; corola de estivación imbricada, con 4 pétalos libres, obovados, verdes, ciliados en el borde; androceo de 15 a 21 estambres, glabros; anteras basifijas; gineceo sobre un ginóforo rosado; ovario cilíndrico; estigma discoidal, sésil; fruto capsular, cilíndrico, moniliforme, dehiscente, liso, castaño oscuro; semillas variables en número, elipsoidales; arilo escaso, de color crema; embrión de color verde (figura 12).

Distribución global: Trinidad, Tobago, Curazao, Bonaire, Colombia y Venezuela.

Hábitat: Bosques deciduos y espinares. Hasta altitudes de $248 \mathrm{~m}$.

Nombre común: Alquitrán.

Usos: No conocidos.

Ejemplares examinados: ATLÁNTICO: Ciudad Barranquilla: Llanada Juanmina, $10 \mathrm{msnm}, 19 \mathrm{Mar}$ 1963, veg., A. Dugand 6233 (COL, DUGAND). Municipio Candelaria: 50 msnm, 11 Ene 1941, b. fl., A. Dugand \& R. Jaramillo 2787 (COL). Municipio Juan de Acosta: Reserva campesina La Montaña, 28 May 2003, veg., H. Cuadros 5786 (DUGAND); 245 msnm, 14 Mar
2015, b. fl., A. Aguirre D. \& E. Ortíz 26 (DUGAND); Serranía de Pajuancho, 248 msnm, 20 Nov 2002, veg., H. Cuadros 5752 (DUGAND). Municipio Puerto Colombia: 10 msnm, 06 Jul 1963, fr., H. McKee 10434 (COL); Loma la Risota, 72 msnm, 17 Jul 2015, fr., A. Aguirre D. \& E. Ortíz 63 (MY, DUGAND). Municipio Tubará: Corrales de San Luis, 01-28 Feb 2008, fr., R. Fonseca \& M. P. Malagón MSP75 (DUGAND); El Morro, 13 Abr 2013, fl., H. Cuadros, A. Aguirre D. \& K. Santana 6431 (DUGAND); Loma Camarón, 23 Nov 2014, veg., A. Aguirre D. \& R. Fonseca 19 (DUGAND).

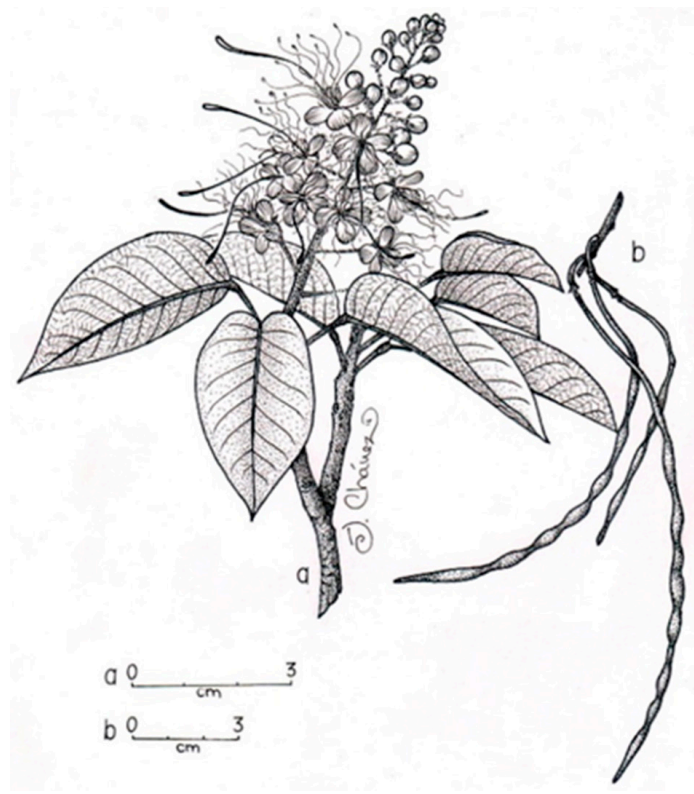

Figura 12. Monilicarpa tenuisiliqua (Jacq.) Cornejo \& Iltis: a. Rama con inflorescencia; b. Frutos; a basado en H. Cuadros, A. Aguirre D. \& K. Santana 6431; b basado en A. Aguirre D. \& E. Ortiz 63.

6. Morisonia L., Sp. Pl. 1: 503. 1753. T.: Morisonia americana $\mathrm{L}$.

6.1. Morisonia americana L., Sp. Pl. 503. 1753.

Capparis morisonia Sw., Observ. Bot. 272. 1791; Morisonia johnstonii Urb., Symb. Antill. 5: 348. 1907; Morisonia elliptica Rusby, Descr. S. Amer. Pl. 24. 1920.

Árbol perennifolio; ramas juveniles con indumento lepidoto peltado-laciniado; hojas alternas, simples; peciolos de tamaño variable con pulvínulo en ambos extremos; lámina juvenil oblonga, y adulta elíptica a ovada, base obtusa a aguda, en algunos casos ligeramente cordada, ápice obtuso, coriácea, juvenil con indumento lepidoto peltado-laciniado y adulta glabra; inflorescencia racimosa en corimbos caulinares, brácteas a lo largo del pedúnculo de ésta; flores hermafroditas, actinomorfas, subtendidas por brácteas diminutas; pedicelo con indumento lepidoto peltado-laciniado; cáliz de estivación cerrada, de 2 a 4 lóbulos irregulares, triangulares, con 
indumento lepidoto peltado-laciniado; glándula nectaria opuesta a cada sépalo y alterna a los pétalos; corola de estivación imbricada, con 4 pétalos libres, verdeamarillentos, en la cara dorsal con abundantes tricomas lepidotos peltados-laciniados, en la cara ventral con tricomas estrellados; androceo de 17 a 24 estambres, glabros; anteras basifijas; gineceo sobre un ginóforo dorado, densamente lepidoto; ovario ovado a globoso, costulado; estigma cupuliforme, sésil; fruto anfisarco, globoso, indehiscente, rugoso, castaño claro a dorado; semillas variables en número, reniformes, inmersas en pulpa cremosa; embrión de color crema (figura 13).

Distribución global: Antillas, Centroamérica, Venezuela, Colombia, Ecuador y las Guayanas.

Hábitat: Bosques deciduos, espinares y cardonales. Hasta altitudes de $500 \mathrm{~m}$.

Nombre común: Níspero de saíno, níspero de monte.

Usos: Fruto ingerido por animales como las ardillas.

Ejemplares examinados: ATLÁNTICO: Municipio Juan de Acosta: Reserva campesina La Montaña, 245 msnm, 14 Mar 2015, veg, A. Aguirre D. \& E. Ortíz 23 (DUGAND). Municipio Piojó: Cerro la Vieja, 500 msnm, 19 Nov 2002, veg., H. Cuadros 5707 (DUGAND). Municipio Tubará: Correg. Guaimaral, 118 msnm, 01-31 May 2015, fr., A. Aguirre D. \& D. Padilla 42 (DUGAND); Loma Camarón, 23 Nov 2014, veg., A. Aguirre D. \& R. Fonseca 12 (DUGAND); 23 Nov 2014, veg., A. Aguirre D. \& R. Fonseca 13 (DUGAND); 23 Nov 2014, veg., A. Aguirre D. \& R. Fonseca 14 (DUGAND).

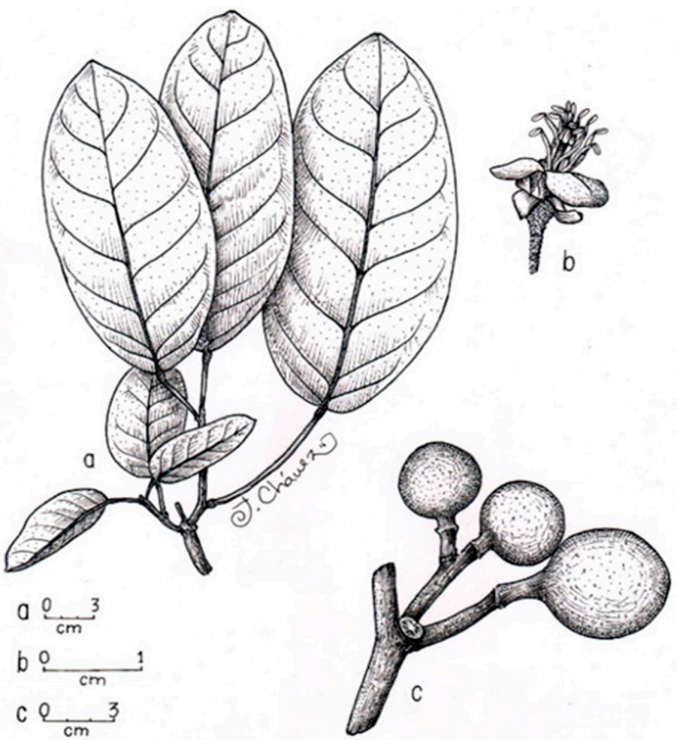

Figura 13. Morisonia americana L.: a. Rama con hojas; b. Flor; c. Frutos; a basado en A. Aguirre D. $\&$ R. Fonseca 14; b basado en material fresco; c basado en A. Aguirre D. \& E. Ortiz 42.
7. Quadrella (DC.) J. Presl, Přir. Rostlin 2: 260. 1825. LT.: Capparis jamaicensis Jacq. [23].

Capparis sect. Quadrella DC., Prodr. 1: 251. 1824; Capparis subg. Quadrella (DC.) Eichler en Martius, Fl. Bras. 13: 269. 1865.

\section{Clave para el género Quadrella en el departamento} del Atlántico.

1. Hojas papiráceas. Ginóforo presente. Q. indica

1’. Hojas papiráceas a coriáceas. Ginóforo ausente. Q. odoratissima

7.1. Quadrella indica (L.) Iltis \& Cornejo, J. Bot. Res. Inst. Texas 4(1): 126-127. 2010.

Breynia indica L., Sp. Pl. 503. 1753; Capparis breynia L., Syst. Nat. ed. 10 2: 1071. 1759; Capparis amygdalifolia Jacq., Enum. Syst. Pl. 24. 1760; Capparis amygdalina Lam., Encycl. 1: 608. 1785; Capparis barcellonensis Kunth, Nov. Gen. Sp. 5: 97. 1821; Capparis breynia var. uniflora DC., Prodr. 1: 252. 1824; Capparis furfuracea Ruiz \& Pav. ex DC., Prodr. 1: 252. 1824; Quadrella breynia J.Presl, Prir. Rostlin 2: 261. 1825; Quadrella furfuracea (Ruiz \& Pav. ex DC.) J.Presl, Prir. Rostlin 2: 260. 1825; Pleuteron breynia Raf., Sylva Tellur. 109. 1838; Uterveria breynia Bertol., Hort. Bonon. P1. Nov. 2: 10. 1839; Colicodendron breynia (L.) Endl., Cat. Horti Vindob. 2: 264. 1842; Pseudocroton tinctorius Müll.Arg., Flora 55: 24. 1872; Capparis indica (L.) Druce, Rep. Bot. Exch. Club Soc. Brit. Isles 3: 415. 1913 publ. 1914; Capparis indica (L.)Fawcett \& Rendle, J. Bot. 52: 144. 1914; Capparis tonduzii Briq., Conserv. Jard. Bot. Genève 17: 391. 1914; Linnaeobreynia indica (L.) Hutch., Gen. Fl. Pl. 2: 311. 1967; Linnaeobreynia tonduzii (Briq.) Hutch., Gen. Fl. Pl. 2: 310. 1967.

Árbol perennifolio; tallo oscuro; ramas con indumento lepidoto de color plateado a ligeramente dorado; hojas alternas, simples, con par de estípulas diminutas; lámina elíptica a obovada, base cuneada y ápice agudo o raramente obtuso, papirácea, indumento de tricomas estrellados en el haz (evidente en hojas jóvenes) y lepidoto en el envés; hojas juveniles conduplicadas. Inflorescencia racimosa en corimbos axilares y terminales; flores hermafroditas, actinomorfas, subtendidas por brácteas diminutas; cáliz de estivación abierta, de 4 sépalos libres apenas unidos en la base, triangulares, con indumento lepidoto en la cara dorsal y estrellado en la cara ventral; escamas nectaríferas opuestas 
a los sépalos y alternas a los pétalos; corola de estivación imbricada, con 4 pétalos libres, obovados, crema, con indumento estrellado; androceo de 14 a 19 estambres, pubescentes; anteras dorsifijas; gineceo sobre un ginóforo crema; ovario cilíndrico; estigma inconspicuo, sésil; fruto capsular, algo carnoso, cilíndrico, toruloso, dehiscente, dorado, endocarpo anaranjado; semillas variables en número, elipsoidales a ovoides, con arilo anaranjado; embrión de color verde (figura 14).

Distribución global: Antillas, Centro América, Colombia y Venezuela.

Hábitat: Bosques deciduos, semideciduos, de galería y espinares. Hasta altitudes de $521 \mathrm{~m}$.

Nombre común: Olivo macho.

Usos: Especie ornamental adornando jardines y avenidas en la ciudad de Barranquilla.

Ejemplares examinados: ATLÁNTICO: Ciudad Barranquilla: Barrio el Prado, 65 msnm, 06 Jun 1937, fl., A. Dugand 1093 (COL); Sabanilla, 50 msnm, 07 Jul 1963, fr., H. S. McKee 10446 (COL). Municipio Juan de Acosta: Reserva campesina La Montaña, SD, fr., E. Ortíz CAP1 (DUGAND). Municipio Luruaco: Reserva Los Rosales, $37 \mathrm{msnm}$, 20 Jul 2015, fr., A. Aguirre D. \& E. Ortíz 70 (MY); Vereda Mateo, 01 Ago 2012, veg., S. Villalobos 289 (DUGAND). Municipio Piojó: Correg. Guaibana, 08 Jun 2006, b.fl., C. Olaciregui C12 (DUGAND); Cerro El Palomar, 27 Ago 2011, fr., C. Castellanos, T. Riveros, L. Olivares CCC599 (COL); 172 msnm, 03 May 2015, fl., A. Aguirre De la Hoz 84 (DUGAND); Cerro la Vieja, $500 \mathrm{msnm}, 19$ Nov 2002, veg., H. Cuadros 5710 (DUGAND). Municipio Puerto Colombia: 19 Abr 1974, b. fl., T. Plowman SD (COL). Municipio Repelón: Cerro Grande, 521 msnm, 20 Jul 2015, veg., A. Aguirre D. \& E. Ortíz 73 (MY). Municipio Sabanagrande: $20 \mathrm{msnm}, 15$ Mar 1953, fl., A. Dugand 4611 (COL). Municipio Tubará: Corrales de San Luis, 01-28 Feb 2008, fr., R. Fonseca \& M. P. Malagón MSP84 (DUGAND); El Morro, 13 Abr 2013, b.fl., H. Cuadros, A. Aguirre D. \& K. Santana 6432 (DUGAND); $151 \mathrm{msnm}, 08$ Nov 2014, veg., A. Aguirre D. \& J. Díaz 01 (DUGAND); Loma Camarón, 23 Nov 2014, veg., A. Aguirre D. \& R. Fonseca 9 (DUGAND); 23 Nov 2014, veg., A. Aguirre D. \& R. Fonseca 17 (DUGAND). Municipio Usiacurí: Luriza, 196 msnm, 23 Abr 2010, b. fl., K. Banda-R., M. Alexander \& L. Olivares KBR192 (COL).

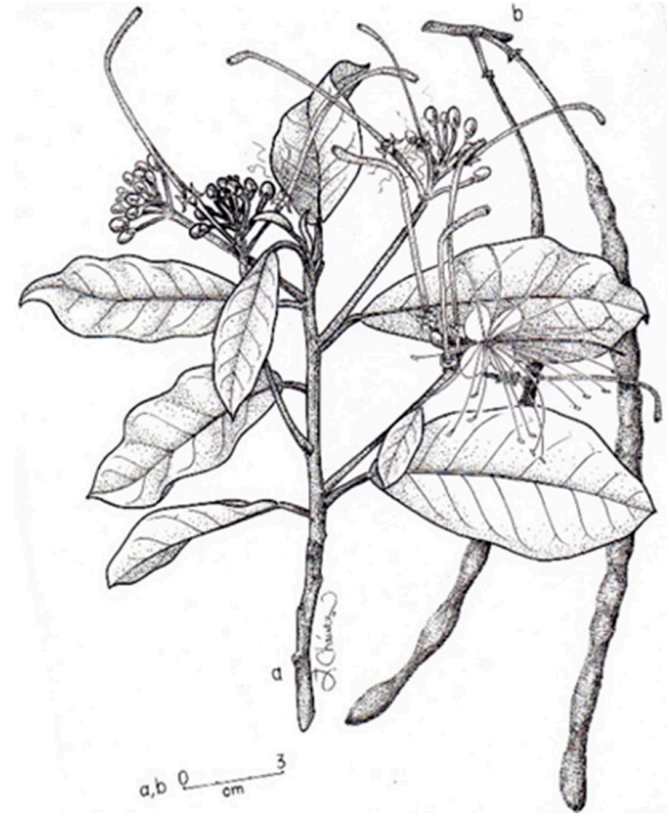

Figura 14. Quadrella indica (L.) Iltis \& Cornejo: a. Rama con flores y botones florales; b. Frutos; a basado en material fresco; b basado en A. Aguirre D. \& E. Ortiz 70

7.2. Quadrella odoratissima (Jacq.) Hutch., Gen. Fl. Pl. 2: 308. 1967.

Capparis odoratissima Jacq., Pl. Hort. Schoenbr. 2: 57. t. 110. 1797; Capparis breynia sensu Kunth, Nov. Gen. Sp. 5: 97. 1821, non L.; Capparis intermedia Kunth, Nov. Gen. Sp. 5: 98. 1821; Quadrella intermedia (Kunth) J.Presl, Prir. Rostlin 2: 261. 1825; Colicodendron lepidotum Turcz., Bull. Soc. Imp. Naturalistes Moscou 27(2): 327. 1854; Capparis ferruginea Willd. ex Eichler, Fl. Bras. 13(1): 271. 1865; Capparis torulosa Griseb. ex Hemsl., Biol. Cent.-Amer., Bot. 1: 44. 1879; Capparis lepidota (Turcz.) Knuth, Repert. Spec. Nov. Regni Veg. Beih. 43: 347. 1927.

Árbol perennifolio; tallo oscuro; ramas con indumento lepidoto de color dorado; hojas alternas, simples, con par de estípulas diminutas; lámina elíptica a obovada u ovada, base cuneada a obtusa y ápice agudo a obtuso, papirácea a coriácea, indumento lepidoto en el envés; hojas juveniles conduplicadas. Inflorescencia racimosa en corimbos axilares y terminales; flores hermafroditas, actinomorfas, subtendidas por brácteas diminutas; cáliz de estivación valvada, de 4 sépalos libres, oblongos a elipsoidales, con indumento lepidoto-peltado en la cara dorsal y tricomas estrellados en la cara ventral; escamas nectarias opuestas a los sépalos y alternas a los pétalos; corola de estivación imbricada, con 4 pétalos libres, circulares a obovados, indumento 
lepidoto en la cara dorsal, blancos y tornándose morados en su senescencia; androceo de 22 a 25 estambres; filamento densamente pubescente en la base, con tricomas estrellados; anteras dorsifijas; gineceo sésil por ausencia de ginóforo; ovario cilíndrico, dorado por la presencia de indumento lepidoto; estigma discoidal, sésil; fruto capsular, algo carnoso, cilíndrico, toruloso, dehiscente, plateado, endocarpo anaranjado; carpóforo ausente; semillas variables en número, ovoides, con arilo anaranjado; embrión de color verde (figura 15).

Distribución global: Antillas, Centro América, Colombia y Venezuela.

Hábitat: Bosques deciduos, espinares y cardonales. Hasta altitudes de $151 \mathrm{~m}$.

Nombre común: Olivo.

Usos: Durante celebraciones religiosas en Semana Santa es utilizada como símbolo de paz y armonía. Además, es una especie ornamental importante en los jardines y avenidas en la ciudad de Barranquilla.

Ejemplares examinados: ATLÁNTICO: Ciudad Barranquilla: 10 msnm, 29 Abr 1960, b. fl., L. E. Mora 1449 (COL); Autopista aeropuerto, 20 msnm, 3 Jul 1995, fr., J. Acuña 5 (DUGAND); Cementerio municipal, 02 Ago 2015, fl./fr., A. Aguirre D. 92 (DUGAND); Ciénaga de Mallorquín, 2002, fr., M. Salazar 122 (DUGAND). Municipio Juan de Acosta: Reserva campesina La Montaña, SD, veg., E. Ortíz CAP2 (DUGAND). Municipio Luruaco: Ciénaga de Luruaco, $25 \mathrm{msnm}, 24$ May 2015, veg., A. Aguirre D. \& E. Ortíz 36A (MY). Municipio Puerto Colombia: 23 Jul 1943, fl./fr., A. Dugand \& R. Jaramillo 3232 (COL); $10 \mathrm{msnm}, 06$ Jun 1963, b. fl., H. S. Mckee 10436 (COL); Loma la Risota, 72 msnm, 21 Mar 2015, fl., A. Aguirre D. \& E. Ortíz 32 (MY). Municipio Tubará: El Morro, 151 msnm, 08 Nov 2014, veg., A. Aguirre D. \& J. Díaz 2 (DUGAND); 08 Nov 2014, fr., A. Aguirre D. \& J. Díaz 3 (DUGAND, MY); 08 Nov 2014, fr., A. Aguirre D. \& J. Díaz 4 (DUGAND); 08 Nov 2014, fr., A. Aguirre D. \& J. Díaz 5 (DUGAND). Municipio Usiacurí: 50 msnm, 02 Ene 1949, veg., J. Araque \& F. A. Barkley 19At066 (COL, FMB).

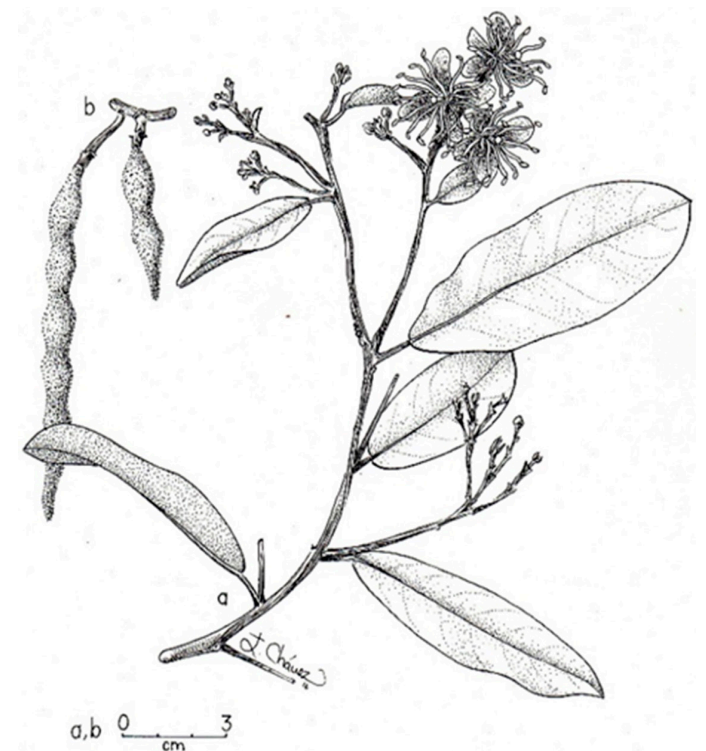

Figura 15. Quadrella odoratissima (Jacq.) Hutch.: a. Rama con flores y botones florales; b. Frutos; a basado en A. Aguirre D. \& E. Ortiz 32; b basado en A. Aguirre D. \& J. Díaz 03.

\section{Consideraciones Finales}

Actualmente, la nomenclatura de los taxones de la familia Capparaceae ha cambiado debido a estudios moleculares y morfológicos, particularmente en el género Capparis L. s.l., el cual ha quedado restringido al Viejo Mundo [10,30]. En el Nuevo Mundo, las especies anteriormente incluidas en Capparis s.l. han sido reubicadas por Cornejo e Iltis $[11,13,14,15,16,17,19,20]$, Iltis y Cornejo [12,21,22] y Cornejo et al. [18] en otros géneros nuevos, resucitados o renombrados.

Para Colombia, Dugand [35] publicó una sinopsis del género Capparis en el que registró 13 especies para el departamento del Atlántico, entre éstas hay dos especies que no fueron encontradas durante las salidas de campo: Calanthea pulcherrima (Jacq.) Miers y Cynophalla amplissima (Lam.) Iltis \& Cornejo. La primera, según bibliografía, crece en Venezuela a altitudes de 600 a $700 \mathrm{msnm}$ en matorrales xerofíticos [52], aunque, Dugand (A. Dugand y R. Jaramillo 2785) la recolectó en el departamento a una altitud de 30 a $50 \mathrm{msnm}$; la localidad actualmente está urbanizada. La segunda crece en bosques semi-deciduos a perennifolios de 
altitudes de 50 a 300 msnm [26], no obstante, Dugand (A. Dugand 571) la recolectó a una elevación de 30 msnm en una localidad cercana al Río Magdalena que hoy en día se encuentra urbanizada y con alto grado de antropización. A partir de estas dos muestras, algunos autores como Romero Castañeda [39] y, Pizano y García [41] han citado dichas especies como presentes en el departamento del Atlántico. Al haberse urbanizado las áreas donde crecían, aparentemente, dichas especies han desaparecido del citado departamento.

Así mismo, el libro de Bosque seco tropical en Colombia [41] registra 13 especies de Capparaceae para el departamento del Atlántico, entre las que está Capparidastrum macrophyllum (Kunth) Hutch. basándose en la exsicatum que se encuentra en el herbario FMB (Fred A. Barkley y Gabriel Gutierrez V. 1843) identificada con ese nombre. Durante la visita a éste se analizó tal espécimen, el cual pertenece a la especie C. pachaca. Adicional a esto, en COL se encontró un duplicado, identificado como C. pachaca.

En el caso del departamento del Atlántico, la familia Capparaceae presenta una amplia distribución en este: en la zona de mar, se encuentra la mayoría de las especies con excepción de $C$. polyantha y $C$. sessilis; la especie $C$. linearis tiene una distribución restringida a este tipo de paisaje; en cambio, en la zona del río Magdalena, la especie con mayor grado de distribución es C. tapia ya que la mayoría de los individuos colectados de esta especie fueron hallados en esta zona. La especie Cynophalla polyantha, mencionado por primera vez para el área de estudio, anteriormente considerada como una subespecie de Capparis flexuosa (C. flexuosa subsp. polyantha (Triana \& Planch.) Iltis). Esta especie presenta una distribución disjunta, en países como Colombia, Venezuela y Bolivia [13,53]; en Colombia ha sido registrada en los departamentos de Antioquia, Bolívar, Cundinamarca, Magdalena y Valle del Cauca. Dentro del departamento del Atlántico, $C$. polyantha habita en bosques de galerías en los bordes de quebradas y cercano a cuerpos de agua como el Embalse del Guájaro y la ciénaga de San de Tocagua; también fue hallado colindante a cuneta de carretera en el municipio de Sabanalarga.

\section{Agradecimientos}

Especialmente al profesor Hermes Cuadros de la Universidad del Atlántico por haberme guiado en mi formación como profesional. A los profesores Luis Carlos Jiménez y Carlos Parra por permitirme el ingreso al Herbario COL para la revisión de la colección, así como a Humberto Mendoza, curador del herbario FMB. Agradecimientos también a Rodian Fonseca y Edgar Ortíz por sus asesorías y ayudas en campo, y a Joel Chávez por las ilustraciones de las especies.

\section{Referencias}

[1] The Angiosperm Phylogeny Group (APG), "An update of the angiosperm phylogeny group classification for the orders and families of flowering plants: APG III", Bot. J. Linnean. Soc. vol. 161, pp. 105-121, 2009. Doi: 10.1111/j.1095-8339.2009.00996.x

[2] The Angiosperm Phylogeny Group (APG), “An update of the Angiosperm Phylogeny Group classification for the orders and families of flowering plants: APG I", Bot. J. Linnean. Soc. vol. 181, pp. 1-20, 2016. Doi: http://dx.doi. org/10.1111/boj. 12385

[3] A. L. Jussieu de, "Genera plantarum". París, 1789, pp. 242-246.

[4] A. P. De Candolle, "Prodomus systematis naturalis regni vegetabilis". París, 1824, pp. 748.

[5] G. Bentham and J. D. Hooker, "Genera Plantarun". in: Londres, Herbariis kewensibus servata, 1862, pp. 454.

[6] A. Eichler, "Capparideae". in: C De Martius \& A Eichler (eds.). Flora Brasiliensis, vol. 13, 1865, pp. 238-292.

[7] J. Lanjow and T. A. Sprague, "International Rules of Botanical Nomenclature". Brittonia vol. 6 (1), 1947, pp. 1-120.

[8] International Association for Plant Taxonomy, "Code International de la Nomenclature Botanique". Montreal, Regn. Veget., 1961, pp. 361.

[9] J. Hall, J. Sytsma and H. H. Iltis, "Phylogeny of Capparaceae and Brassicaceae based on Chloroplast sequence data", Am. J. Bot., vol 89 (11), pp. 1826-1842, 2002. Doi: http://dx.doi. org/10.3732/ajb.89.11.1826

[10] J. Hall, "Systematics of Capparaceae and Cleomaceae evaluation of the generic delimitations of Capparis and Cleome using plastid DNA sequence data", Botany, vol. 86, pp. 682-696, 2008.

[11] X. Cornejo and H. H. Iltis, "New combinations in Capparaceae sensu stricto for flora of 
Ecuador", Harvard Pap. Bot., vol. 11(1), pp. 1718, 2006. Doi: http://dx.doi.org/10.3100/10434534(2006)11\%5B17:NCICSS\%5D2.0.CO;2

[12] H. H. Iltis and X. Cornejo, "Studies in the Capparaceae XXX: Capparicordis, a new genus from the neotropics", Brittonia, vol. 59, pp. 245254, 2007. Doi: http://dx.doi.org/10.1663/0007196X(2007)59\%5B245:SITCXC\%5D2.0.CO;2

[13] X. Cornejo and H. H. Iltis, "New combinations in South American Capparaceae" Harvard Pap. Bot., vol. 13(1), pp. 117-120, 2008. Doi: http:// dx.doi.org/10.3100/1043-4534(2008)13\%5B117 :NCISAC \%5D2.0.CO;2

[14] X. Cornejo and H. H. Iltis, "A revision of the American species of the genus Crateva (Capparaceae)", Harvard Pap. Bot., vol. 13(1), pp. 121-135, 2008. Doi: http://dx.doi. org/10.3100/1043-4534(2008)13\%5B121:ARO TAS\%5D2.0.CO;2

[15] X. Cornejo and H. H. Iltis, "The reinstatement of Capparidastrum (Capparaceae)". Harvard Pap Bot., vol. 13(2), pp. 229-236, 2008. Doi: http:// dx.doi.org/10.3100/1043-4534-13.2.229

[16] X. Cornejo and H. H. Iltis, "Two new genera of Capparaceae: Sarcotoxicum and Mesocapparis Stat. Nov., and the reinstatement of Neocalyptrocalyx", Harvard Pap. Bot., vol. 13(1), pp. 103-116, 2008. Doi: http://dx.doi. org/10.3100/1043-4534(2008)13\%5B103:TNG OCS\%5D2.0.CO;2

[17] X. Cornejo and H. H. Iltis, "A revision of Colicodendron Mart. (Capparaceae s.s.)", J. Bot. Res. Inst. Texas., vol. 2(1), pp. 75-93, 2008.

[18] X. Cornejo, H. H. Iltis y S. Tomb, “Anisocapparis $y$ Monilicarpa: Dos nuevos géneros de Capparaceae de América del Sur", J. Bot. Res. Inst. Texas., vol. 2(1), pp. 61-74, 2008.

[19]X.Cornejo and H. H, Iltis, "Hispaniolanthus: Anew genus of Capparaceae endemic to Hispaniola", Harvard Pap. Bot., vol. 14(1), pp. 117-120, 2009. http://dx.doi.org/10.3100/025.014.0103

[20] X. Cornejo and H. H. Iltis, "The reinstatement of Beautempsia (Capparaceae) and a key to the genera of Neotropical Capparaceae with variously stellate or peltate indumenta", J. Bot. Res. Inst. Texas, vol. 3(2), pp. 683-689, 2009.

[21] H. H. Iltis and X. Cornejo, "Studies in the Capparaceae XXIX: Synopsis of Quadrella, A Mesoamerican and West Indian genus", $J$. Bot. Res. Inst. Texas, vol. 4(1), pp. 117-132, 2010. Doi: http://dx.doi.org/10.3417/10553177(2007)17[452:SITCXA]2.0.CO;2
[22] H. H. Iltis and X. Cornejo, "Two new genera and three new combinations in Neotropical Capparaceae" Harvard Pap. Bot., vol. 16(1), pp. 65-70, 2011. Doi: http://dx.doi. org/10.3100/025.016.0110

[23] X. Cornejo and H. H. Iltis, "New combinations in Capparaceae for flora Mesoamericana", Harvard Pap. Bot., vol. 18 (2), pp. 147, 2013. Doi: http://dx.doi.org/10.3100/025.018.0208

[24] H. K. Airy-Shaw, "A Dictionary of the flowering plants \& ferns". 7 Ed. Londres: Cambridge University Press, 1966, pp. 194-195, 254.

[25] J. Hutchinson, "Capparidaceae" in The genera of Flowering plants, 2 Ed. Londres: Oxford University Press, 1967, pp. 303-317.

[26] T. Ruiz Zapata and H. H. Iltis, "Capparaceae". In Flora of the Venezuelan Guayana, P. Berry, B. Holst \& K. Yatskievych (Eds.), St. Louis, Missouri: Missouri Botanical Garden Press, 1998, vol. 4, pp. 132-157.

[27] L. Cumana, "La familia Capparaceae depositada en el Herbario IRBR de los estados Anzoátegui y Sucre, Venezuela", Saber, vol. 15(1-2), pp. 15-22, 2003.

[28] T. Ruiz Zapata, "Capparis L. (CapparoideaeCapparaceae) en el Estado Trujillo, Venezuela", Ernstia vol. 15 (1-4), pp. 27-50, 2005.

[29] C. Inocencio, D. Rivera, M. Obón, F. Alcaraz and J. A. Barreña, "A systematic revision of Capparis Section Capparis (Capparaceae)", Ann. Mo. Bot. Gard., vol. 93(1), pp. 122-149, 2006.

[30] X. Cornejo y H.H. Iltis, "Capparaceae" en: Flora de Jalisco y área colindante, Fascículo 25, México: Universidad de Guadalajara, 2012, pp. 65.

[31] T. Ruiz Zapata. "Los géneros de las plantas de la familia Capparidaceae de Venezuela", Biollania, vol. 13, pp. 33-46, 1997.

[32] T. Ruiz Zapata, "Capparidaceae venezolanas y sus usos". Memorias del Instituto de Biología Experimental, IBE, Venezuela, Vol. 2: 157160, 1999.

[33] L. Cumana y R. Delgado, "Especies maderables usadas en construcción naval en el golfo de Cariaco y la península de Araya, Estado de Sucre, Venezuela", Saber, vol. 8, pp. 36-45, 1996.

[34] M. P. Cruz, A. C. Estupiñán, N. JiménezEscobar, N. Sánchez, G. Galeano y E. Linares, "Etnobotánica de la región tropical del Cesar, Complejo ciénaga de Zapatosa", in Colombia: Diversidad biótica VIII: Media y baja montaña 
de la Serranía de Perijá, J. O. Rangel-Ch., Bogotá: Universidad Nacional de Colombia, 2009, pp. 417-447.

[35] A. Dugand, "El género Capparis en Colombia". Caldasia vol. 1 (2), pp. 29-54, 1941.

[36] A. Dugand, "Capparidaceae: Stuebelia Pax sinónimo de Belencita Karst". Caldasia vol 2 (9), pp. 371-373, 1944.

[37] A. Dugand, "Noticias botánicas Colombianas X”. Caldasia vol. 21 (5), pp. 55-58, 1948.

[38] A. Dugand, "Acerca de unas Capparis de la flora Colombiana”. Caldasia vol. 47 (5), pp. 219-229, 1968.

[39] R. Romero Castañeda, "Capparidáceas", in Flora del Centro de Bolívar, R. Romero Castañeda, Bogotá, 1965, pp. 59-79.

[40] G. Rodríguez, K. Banda-R y S. Reyes, "Lista comentada de las plantas vasculares de bosques secos prioritarios para la conservación en los departamentos de Atlántico y Bolívar (Caribe colombiano)". Biota Colombiana vol. 13 (2), pp. 7-39, 2012.

[41] C. Pizano y H. García (editores), "El Bosque Seco Tropical en Colombia”, Bogotá: IAvH, 2014, pp. 349.

[42] IDEAM, Datos ambientales [online]. Colombia: IDEAM, 2016 Disponible en: http://www. ideam.gov.co/documents/21021/21789/ Promedios+81-10.xlsx/0f4e516b-84ab-4c919549-180e62b693ee

[43] IGAC, "Atlántico, Características geográficas", IGAC: Bogotá, 1994, pp. 19-57.
[44] J. O. Rangel-Ch y A. Velázquez, "Métodos de estudio de la vegetación", in Colombia: Colombia diversidad biótica II: Tipos de vegetación en Colombia, J. O. Rangel-Ch, P. Lowy C. y M. Aguilar, Bogotá: Universidad Nacional de Colombia, 1997, pp. 59-87.

[45] T. Ruiz Zapata, "Capparaceae del Parque Nacional Henri Pittier, Venezuela", Ernstia vol. 12 (3-4), pp. 137-172, 2002.

[46] Tropicos.org, [online]. Missouri Botanical Garden, 2016. Disponible en: http://www. tropicos.org

[47] The Plant List. Version 1.1, [online]. 2013. Disponible en: http://www.theplantlist.org/

[48] Jstor Global Plant, [online]. 2016. Disponible en: https://plants.jstor.org/

[49] C. Linneo, "Systema Naturae", Ed. 10, 1759, pp. 1044.

[50] C. Linneo, "Species Plantarum", Estocolmo, 1753, pp. 444

[51] X. Cornejo and H.H. Iltis, "Lectotypification and a new combination in Cynophalla (Capparaceae)", Rodriguesia, vol. 61 (1), pp. 153-155, 2010.

[52] T. Ruiz Zapata, "Capparis L. subgénero Calanthea DC. en Venezuela", Ernstia, vol. 26(2), pp. 113-127, 2006.

[53] L. A. Galetti, V. Y. Mogni, L. J. Oakley, R. T. Pennington y D. E. Prado, "Cynophalla polyantha (Capparaceae), nuevo registro para la flora Argentina", Bol. Soc. Argent. Bot., vol. 51(2), pp. 373-378, 2016. 
